\title{
Reciprocating Thermal Behavior in Multichannel Relaxation of Cobalt(II) Based Single Ion Magnets
}

\author{
Cyril Rajnák @, Ján Titiš and Roman Boča * \\ Department of Chemistry, Faculty of Natural Sciences, University of SS Cyril and Methodius, \\ 91701 Trnava, Slovakia; cyril.rajnak@ucm.sk (C.R.); jan.titis@ucm.sk (J.T.) \\ * Correspondence: roman.boca@ucm.sk
}

check for

updates

Citation: Rajnák, C.; Titiš, J.; Boča, R. Reciprocating Thermal Behavior in

Multichannel Relaxation of Cobalt(II) Based Single Ion Magnets.

Magnetochemistry 2021, 7, 76. https:// doi.org/10.3390/magnetochemistry 7060076

Academic Editors: Boris Tsukerblat, Andrew Palii and Elena Garlatti

Received: 9 March 2021

Accepted: 18 May 2021

Published: 25 May 2021

Publisher's Note: MDPI stays neutral with regard to jurisdictional claims in published maps and institutional affiliations.

Copyright: (c) 2021 by the authors. Licensee MDPI, Basel, Switzerland. This article is an open access article distributed under the terms and conditions of the Creative Commons Attribution (CC BY) license (https:// creativecommons.org/licenses/by/ $4.0 /)$.
Abstract: A series of mononuclear Co(II) complexes showing slow magnetic relaxation is assessed from the point of view of relaxation mechanisms. In certain cases, the reciprocating thermal behavior is detected: On cooling, the slow relaxation time is prolonged until a certain limit and then, unexpectedly, is accelerated. The low-temperature magnetic data can be successfully fitted by assuming Raman and/or phonon bottleneck mechanisms of the slow magnetic relaxation for the high-frequency relaxation channel. An additional term with the negative temperature exponent is capable of reproducing the whole experimental dataset.

Keywords: slow magnetic relaxation; single ion magnets; reciprocating thermal behavior; cobalt(II) complexes

\section{Introduction}

Single molecule (SMM), single chain (SCM), and single ion (SIM) magnets represent a class of coordination compounds based upon transition metal and/or lanthanide complexes that are promising in their technical utilization as carriers of information possessing a giant memory capacity [1-10]. During the last decade, a plethora of publications have been oriented to this subject and these new objects also brought novel physical effects, e.g., quantum tunneling of magnetization. Properties of SMMs, SCMs, and SIMs have been subjected to a number of reviews, e.g., [11-15].

For this still developing field, experimental data bring new information which neither conforms expectations nor existing theories. Among new observations, a reciprocating thermal behavior (RTB) has been reported recently [16,17]. In complexes showing the slow magnetic relaxation, usually detected by the AC (Alternating Current) susceptibility measurements as a function of the frequency of the oscillating field, a "normal" behavior is recorded when the relaxation time on cooling increases, irrespective of the particular mechanism - Orbach, Raman, and direct. Eventually, it reaches a temperature independent plateau when only the quantum tunneling of magnetization occurs. It is observed that a number of studied systems showing the slow magnetic relaxation display an anomaly below some temperature limit: On further cooling the relaxation time $\tau$ decreases. This effect can be phenomenologically described by a new relaxation term with the negative temperature exponent: $\tau^{-1} \sim T^{-k}$. Such a temperature evolution is predicted by the second solution of the phonon bottleneck effect that is, to our best knowledge, ignored so far.

Herein, we are reviewing the most important mechanisms that influence the slow magnetic relaxation, namely Orbach, Raman, direct, phonon bottleneck, and quantum tunneling of magnetization. Their applicability is presented for a set of mononuclear Co(II) complexes showing the slow magnetic relaxation. However, in larger external magnetic fields of $B_{\mathrm{DC}}=0.4-0.6 \mathrm{~T}$, a new, much slower relaxation channel is opened-the lowfrequency (LF) channel. With the increased external field the LF channel tends to dominate over the high-frequency relaxation path. The mole fraction of the slowly relaxing species via the LF channel at a temperature low enough often exceeds $x(\mathrm{LF})>0.8$. It is worth 
noting that just in such a case the HF relaxation channel can display an anomaly-the reciprocating thermal behavior.

\section{Spin-Lattice Relaxation}

The solid-state system that contains magneto-carriers-magnetic moments due to the orbital and spin angular momentum of electrons and nuclei, consists of the assembly of spins and the phonon bath (energy reservoir) due to the vibrations of the solid state, and these are under the influence of external stimuli: Static or oscillating magnetic field, irradiation, and temperature. The overall magnetic polarization is described by the macroscopic magnetization $\mathbf{M}\left(M_{x}, M_{y}, M_{z}\right)$ that from the thermodynamic unstable state relaxes spontaneously in time to the thermodynamic more stable state. In simple words, the relaxation means a recovery of the equilibrium.

When the static magnetic field is on/off the relaxation formula for an ideal case is

$$
M(t)=M_{0}+M_{(t=0)} \exp (-t / \tau)
$$

and for a paramagnetic material in equilibrium $M_{0}=0$ is assumed. The time constant $\tau$ is termed the relaxation time. In practice, the situation is better described by a stretched exponential.

In general, relaxation processes are covered by numerous mechanisms in which the surrounding of the spin system under investigation plays an important role [18,19]. The relaxation mechanisms were considered as principal: The direct, Raman, and Orbach. They used to be completed by the quantum tunneling of magnetization that is temperature independent and manifesting itself at a very low temperature. Some mechanisms are reviewed in Table 1.

Table 1. Important relaxation mechanisms $[18,19]$.

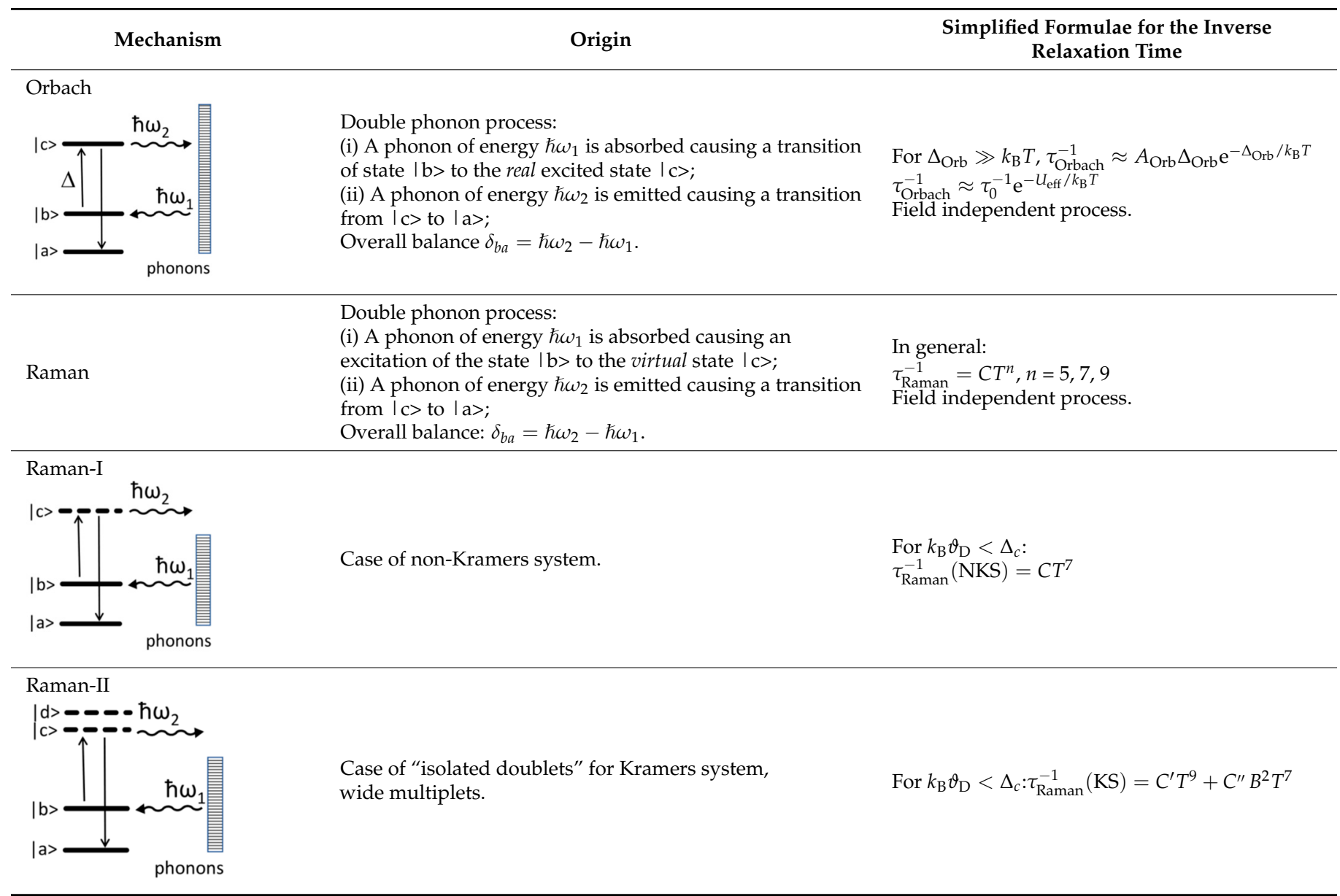


Table 1. Cont.

\begin{tabular}{|c|c|c|}
\hline Mechanism & Origin & $\begin{array}{l}\text { Simplified Formulae for the Inverse } \\
\text { Relaxation Time }\end{array}$ \\
\hline \multirow{2}{*}{\multicolumn{3}{|c|}{$\begin{array}{l}\text { Raman-III, } \\
\text { Orbach-Blume } \\
\mid \mathrm{d}>= \\
\mid \mathrm{b}>> \\
\mid \mathrm{a}>=\end{array}$}} \\
\hline & & \\
\hline 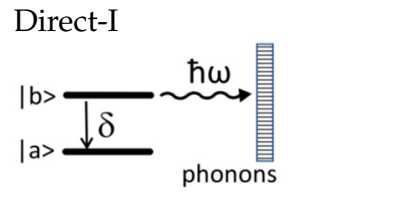 & $\begin{array}{l}\text { Single phonon process: } \\
\text { A phonon of the energy } \delta_{b a}=\hbar \omega \text { is emitted when } \\
\text { the system relaxes from the higher energy level }|\mathrm{b}\rangle \\
\text { to }|\mathrm{a}\rangle \text {. }\end{array}$ & $\begin{array}{l}\text { For non-Kramers system: } \\
\text { (integral spin) } \\
\tau_{\text {direct }}^{-1}(\mathrm{NKS})=A_{\text {dir }} T=A B^{m} T, m=2 \\
\text { Field and temperature dependent process. }\end{array}$ \\
\hline Direct-II & $\begin{array}{l}\text { As above, magnetic energy levels are doubly } \\
\text { degenerate in the absence of the magnetic field. The } \\
\text { field removes the degeneracy. }\end{array}$ & $\begin{array}{l}\text { For Kramers system: } \\
\text { (half integral spin, e.g., } S=3 / 2 \text { ) } \\
\tau_{\text {direct }}^{-1}(\mathrm{KS})=A^{\prime}{ }_{\text {dir }} T=A^{\prime} B^{m} T, m=4\end{array}$ \\
\hline $\begin{array}{l}\text { Quantum tunneling of } \\
\text { magnetization }\end{array}$ & $\begin{array}{l}\text { Temperature independent process via the energy } \\
\text { barrier; } A_{\mathrm{qtm}} \text { - zero-field relaxation rate, }\end{array}$ & $\begin{array}{l}\text { Brons-van Vleck formula [20]: } \\
\tau_{\mathrm{qtm}}^{-1}=A_{\mathrm{qtm}} \frac{\gamma\left(\beta+B^{2}\right)}{\gamma \beta+B^{2}}=d \frac{1+e B^{2}}{1+f B^{2}}\end{array}$ \\
\hline 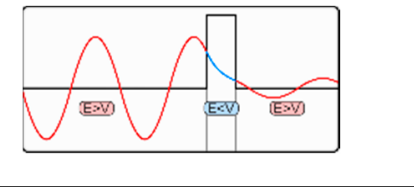 & $\begin{array}{l}\gamma \text {-concentration, and } \beta=b / C \text { is parameter } \\
\text { proportional to the square of the internal field } \\
\text { generated by dipole-dipole, hyperfine, and exchange } \\
\text { interactions; } b \text {-coefficient of the magnetic specific } \\
\text { heat }\left(c_{\mathrm{M}}=b / T^{2}\right) ; C \text { - the Curie constant. }\end{array}$ & $\begin{array}{l}\text { Simplified formula [21]: } \\
\tau_{\mathrm{qtm}}^{-1}=Q_{1} /\left(Q_{2}+B^{2}\right)=D_{\mathrm{qtm}} \\
\text { Field dependent, temperature } \\
\text { independent process. }\end{array}$ \\
\hline $\mid \mathrm{b}>\overbrace{\mid \mathrm{a}}$ Phonon bottleneck I & $\begin{array}{l}\text { The direct process is hindered by the insufficient } \\
\text { heat capacity of the phonon system. }\end{array}$ & $\begin{array}{l}\text { Simplified solution: } \\
\tau_{\mathrm{pb}}^{-1}=G T^{l}, l=2\end{array}$ \\
\hline Phonon bottleneck II & Ignored as too fast. & $\begin{array}{l}\text { Predicted in low temperature regime: } \\
\tau_{\mathrm{pb}}^{-1}=F T^{-k}, k=1\end{array}$ \\
\hline Local vibrational process & $\Delta_{\text {loc }}$-energy of the local mode. & $\tau_{\text {local }}^{-1}=A_{\text {loc }} \frac{\mathrm{e}^{\Delta_{\mathrm{loc}} / k_{\mathrm{B}} T}}{\left(\mathrm{e}^{\Delta_{\mathrm{loc}} / k_{\mathrm{B}} T}-1\right)^{2}}[22]$ \\
\hline Thermally activated process & $\begin{array}{l}E_{\mathrm{a}} \text {-activation energy, } \omega \text {-electron spin } \\
\text { Larmor frequency. }\end{array}$ & $\begin{array}{l}\tau_{\text {therm }}^{-1}=A_{\text {therm }} \frac{2 \tau_{\mathrm{c}}}{1+\left(\omega \tau_{\mathrm{c}}\right)^{2}} \\
\text { correlation time } \tau_{\mathrm{c}}=\tau_{c}^{0} \cdot \mathrm{e}^{E_{\mathrm{a}} / k_{\mathrm{B}} T}\end{array}$ \\
\hline
\end{tabular}

The overall relaxation time results from the summation as follows:

$$
\tau^{-1}=\tau_{\text {Orbach }}^{-1}+\tau_{\text {Raman }}^{-1}+\tau_{\text {direct }}^{-1}+\left(\tau_{\text {phonon_bottleneck }}^{-1}\right)+\tau_{\text {quantum_tunneling }}^{-1}+\tau_{\text {other }}^{-1}
$$

where only selected terms are active in the certain temperature range. (Phonon bottleneck process is considered as a special kind of the direct process.) It must be mentioned that the registered values of relaxation time $\tau$ are not necessarily identical with the time constant $T_{1}$ for an ideal solid.

\section{Phonon Bottleneck Effect}

When analyzing the function $\ln \tau$ vs. $\ln T$, the low-temperature regime is described by straight lines. The greater the temperature, the lower the relaxation time as follows:

(a) The Raman process $\ln \tau_{\text {Raman }}=-\ln C-n \cdot \ln T$ with $n=5-9$;

(b) The direct process $\ln \tau_{\text {direct }}=-\ln A_{\text {dir }}-\ln T$;

(c) The quantum tunneling process $\ln \tau_{\mathrm{qtm}}=-\ln D_{\mathrm{qtm}}$. 
Moreover, the function $\ln \tau_{\text {Orbach }}=\ln \tau_{0}+\left(U_{\text {eff }} / k_{\mathrm{B}}\right) \cdot T^{-1}$ referring to the Orbach process is linear in the high-temperature range. This allows an identification of the relaxation process that dominates in a certain temperature interval (Figure 1).
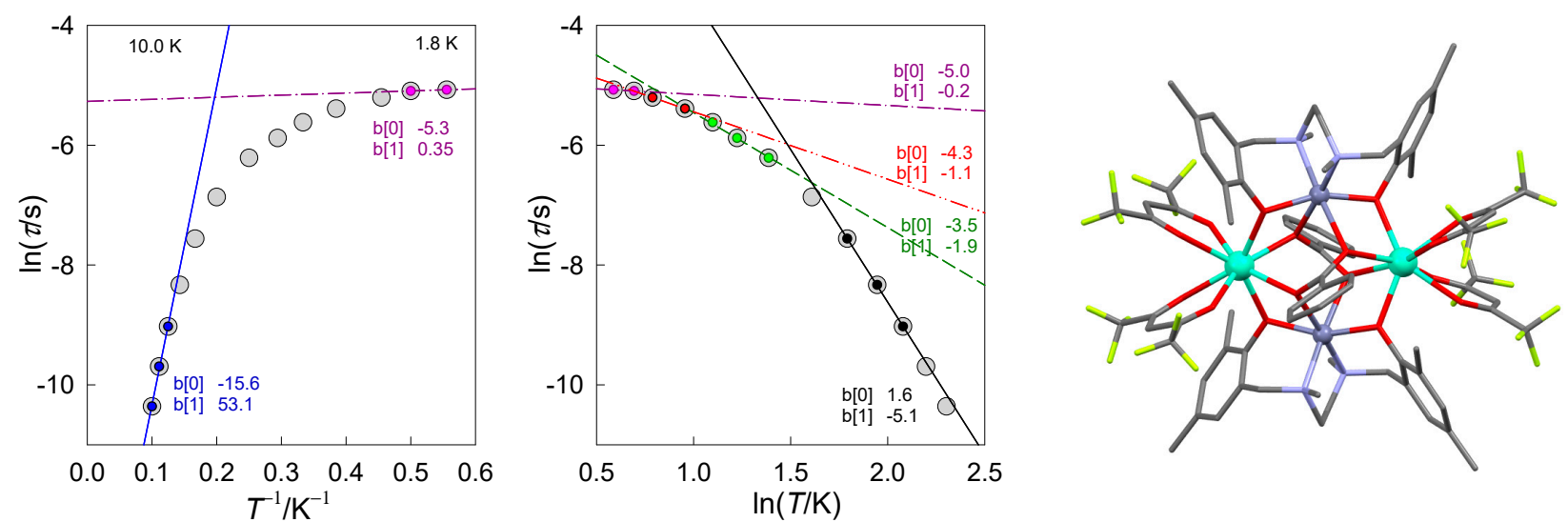

Figure 1. Different contributions to the relaxation time in $\left[\mathrm{Dy}{ }_{2}{ }_{2} \mathrm{Zn}_{2}{ }_{2}\right]$ molecular complex: Orbach (high-temperature, blue, $U_{\text {eff }} / k_{\mathrm{B}}=53 \mathrm{~K}$ ), Raman (intermediate-temperature, black, $n \sim 5$ ), phonon bottleneck (low temperature, green, $n \sim 2$ ), direct (low-temperature, red, $n \sim 1$ ), quantum tunneling of magnetization (violet, $n \sim 0$ ). Straight lines: $y=\mathrm{b}[0]+\mathrm{b}[1] x$. Data adapted from ref. [23]. 2014, American Chemical Society.

The analysis of experimental data shows that in addition to the above mentioned processes there exists another one for which the equation $\ln \tau=-\ln G-l \cdot \ln T$ or $\tau^{-1}=G T^{l}$ is obeyed, but with a subnormal exponent $1 \sim 2$. This indicates a possible presence of the phonon bottleneck effect (note: here we are saying that at a different temperature range a different relaxation "rate" dominates).

The above relaxation mechanisms were based under the assumption that the energy gain given to the phonon system is transferred immediately to the thermal bath of the constant temperature $T_{0}$ and a sufficient (infinite) heat capacity. There are, however, two obstacles. (i) The number of spins in a crystal is ca $10^{21}$ per $\mathrm{cm}^{3}$, whereas the number of available phonon modes at low temperature is significantly lower, by a factor of $10^{6}$ [18]. (ii) The phonons are scattered on the crystal boundary and some of them are backscattered so that they are not deposited to the thermal bath "just in time". Owing to this effect, there is some accumulation of the phonons that do not leave the crystal so that apparently the temperature of the phonon bath $T_{\mathrm{ph}}$ is higher than that of the thermal bath: $T_{\mathrm{ph}}>T_{0}$. This results in an alteration of the direct relaxation process that is termed the phonon bottleneck effect.

As a result, we can speak about the temperature of the spin system $T_{\mathrm{S}}$ and phonon temperature $T_{\mathrm{ph}}$. Accordingly, the heat capacity of the spin system $\left(C_{H}\right)$ is greater than that of the phonon $\left(C_{\mathrm{ph}}\right)$, i.e., $C_{H}>C_{\mathrm{ph}}$ (Figure 2$)$.

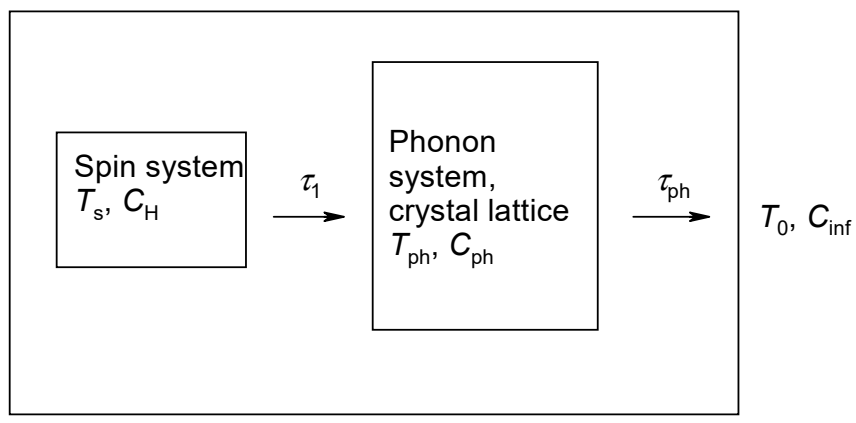

Thermal bath, e.g. the sample chamber

Figure 2. Energy flow from the spin system through the phonon system to the thermal bath. 
Based upon arguments about the heat flow, relationships for two relaxation times (time constants) were derived [18] as solutions of the two time-dependent differential equations:

$$
\begin{gathered}
\tau_{1}^{\prime}=\tau_{1} \cdot C_{\mathrm{ph}} /\left(C_{\mathrm{ph}}+C_{H}\right) \\
\tau_{\mathrm{b}}=\tau_{1}+\tau_{\mathrm{ph}} \cdot\left(C_{\mathrm{ph}}+C_{H}\right) / C_{\mathrm{ph}}
\end{gathered}
$$

Notice that $\tau_{1}$ is the spin to phonon relaxation time and $\tau_{\mathrm{ph}}$ is the phonon to thermal bath relaxation time. The relaxation time $\tau_{1}^{\prime}$ is very short, $\tau_{\mathrm{b}}$ is slower and it refers to a combined spins + phonons relaxation to the thermal bath.

In a microscopic approach, two differential equations were established [24] giving rise to two time constants $\tau_{b}$ and $\tau_{b}^{\prime}$, hence:

$$
\tau_{b}=\tau_{1(\text { direct })}+\tau^{\prime}
$$

with

$$
\begin{gathered}
\frac{1}{\tau^{\prime}}=\frac{1}{\tau_{\mathrm{ph}}} \frac{3 \delta^{2}(\Delta \delta)}{2 \pi^{2} c v^{3} \hbar^{3}} \operatorname{coth}^{2}\left(\delta / 2 k_{\mathrm{B}} T\right) \approx\left[\frac{1}{\tau_{\mathrm{ph}}} \frac{6(\Delta \delta) k_{\mathrm{B}}^{2}}{\pi^{2} c v^{3} \hbar^{3}}\right](T)^{2} \rightarrow G T^{2} \\
\frac{1}{\tau_{b}^{\prime}} \approx\left[\frac{A \pi^{2} c v^{3} \hbar^{3}}{6(\Delta \delta) k_{\mathrm{B}}^{2}}\right](T)^{-1} \rightarrow F T^{-1}
\end{gathered}
$$

Here, $c=N / V$ is the number of spins per $\mathrm{cm}^{3}$ (volume concentration), $\delta=\hbar \omega$ is the ground to excited level separation. In the magnetic field one can use the linewidth $(\Delta \delta)=g \mu_{\mathrm{B}}(\Delta B)$. In the role of $\tau_{\mathrm{ph}}$ a simple formula can be applied $\tau_{\mathrm{ph}} \approx L / 2 v$ where $L$ is the linear dimension of the crystal and the velocity of sound in the crystal is $v \sim 2.5 \times 10^{3} \mathrm{~m}$ $\mathrm{s}^{-1}$ (for $L=1 \mu \mathrm{m}, \tau_{\mathrm{ph}} \sim 10^{-10} \mathrm{~s}$ [18]). The dependence of the relaxation time upon the crystal size proves that the relaxation is driven by PB [25]. Involvement of the magnetic field modifies the formulae for the relaxation time in the presence of the phonon bottleneck as follows:

$$
\begin{gathered}
\frac{1}{\tau^{\prime}} \approx C^{\prime} \frac{g(\Delta B)}{\tau_{\mathrm{ph}} c} T^{2} \rightarrow G_{B} T^{2} \\
\frac{1}{\tau_{b}^{\prime}} \approx C^{\prime \prime} \frac{A c}{(\Delta B) g} T^{-1} \rightarrow F_{B} T^{-1}
\end{gathered}
$$

It was argued [24] that the second solution of the phonon bottleneck differential equations $\tau_{b}^{\prime}$ is by several orders of magnitude smaller so that it could be ignored (in diluted ions). To the best of our knowledge, its effect has not been reported until the discovery of the reciprocating thermal behavior in molecular complexes possessing the intermolecular contacts [26].

\section{Experimental Part}

\subsection{Synthesis, Chemical Analysis, X-ray Structure, and DC-Magnetic Data}

The present communication is a review of the examples where the reciprocating thermal behavior has been detected. The synthetic route and the analytical data can be found in the original publications. The X-ray structure determination has been done in a standard way, preferentially at low temperature, and the principal crystallographic data are deposited in the Cambridge Crystallographic Data Centre. They are available in the "cif" format.

The DC magnetic data were collected with the help of the SQUID apparatus (Quantum Design, MPMS-XL7) restricted to the field $B_{\mathrm{DC}}=7 \mathrm{~T}$ and $T=1.8-400 \mathrm{~K}$. Samples in the form of a fine powder were encapsulated in a gelatin sample holder. In DC magnetic experiments, the small field $B_{\mathrm{DC}}=0.1 \mathrm{~T}$ has been applied in taking the temperature dependence of the static magnetic susceptibility between $T=1.9-300 \mathrm{~K}$. These data were corrected for the underlying diamagnetism. At the same time, magnetization data were taken until $B=7 \mathrm{~T}$ at two temperatures, $T=2.0$ and $4.6 \mathrm{~K}$. The DC magnetic data served for the determination 
of the axial zero-field splitting parameter $D$; their temperature and/or field dependences were displayed in the published material.

\subsection{AC Susceptibility}

The AC susceptibility data were taken with the same SQUID apparatus and the same specimen as above using the working amplitude of $B_{\mathrm{AC}}=0.38 \mathrm{mT}$ and frequencies of the oscillating field $f=0.1-1500 \mathrm{~Hz}$.

The first scan refers to a field dependence of the AC susceptibility at the constant low temperature (say $T_{0}=2.0 \mathrm{~K}$ ) for a set of trial frequencies of the oscillating field: $f_{i}=1.1$, 11, 111, and $1111 \mathrm{~Hz}: \chi^{\prime}=F\left(B, f_{i},\left[T_{0}\right]\right)$ and $\chi^{\prime \prime}=F\left(B, f_{i},\left[T_{0}\right]\right)$. Such graph indicates a field-frequency region where the out-of-phase susceptibility dominates (Figure 3a).
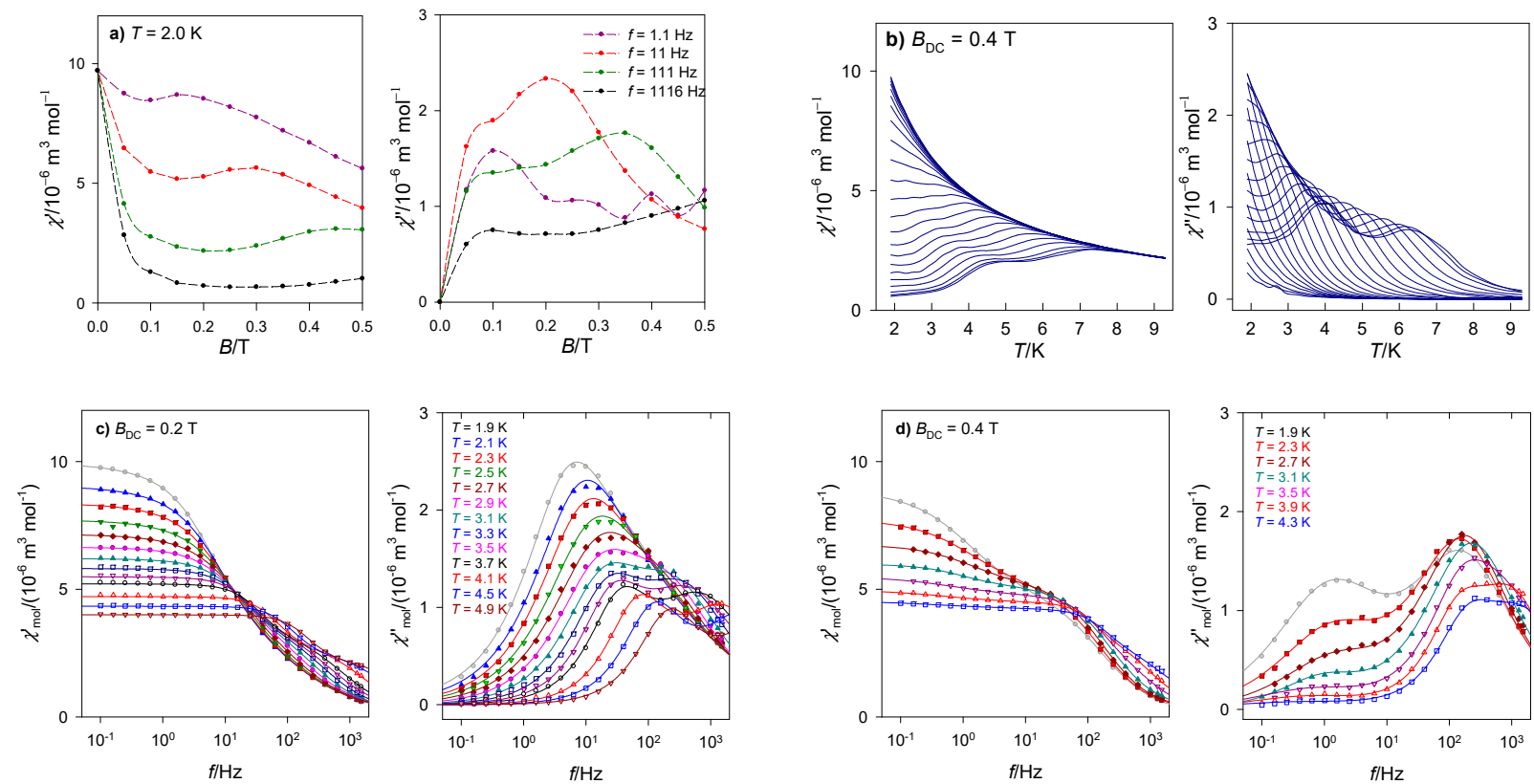

Figure 3. Ways of AC susceptibility data taking/analysis. AC susceptibility components: (a) field dependence, (b) temperature dependence, (c,d) frequency dependence. Data adapted from ref. [27]. 2017, Royal Society of Chemistry.

In the second scan, the frequency dependence of the AC susceptibility is monitored for a set of fixed magnetic fields at the constant low temperature $\chi^{\prime \prime}=F\left(f, B_{i},\left[T_{0}\right]\right)$. The frequencies are selected in such a way that the $x$-axis in the logarithmic scale contains equidistant points. The corresponding graph identifies the number of relaxation channels and their field dependence. The third scan collects the $\mathrm{AC}$ response as a function of temperature for the set of frequencies at the fixed external field. This is useful in identifying the critical point where the functions $\chi^{\prime}=F\left(T, f_{i},\left[B_{0}\right]\right)$ merge and $\chi^{\prime \prime}=F\left(T, f_{i},\left[B_{0}\right]\right)$ vanishes (Figure $3 b)$. Finally, the displayed function are $\chi^{\prime}=F\left(f, T_{i},\left[B_{0}\right]\right)$ and $\chi^{\prime \prime}=F\left(f, T_{i},\left[B_{0}\right]\right)$ that are subjected to the fitting procedure (Figure $3 c, d$ ). This dependence is of a primary interest.

The magnetization measured in the oscillating (AC) magnetic fields

$$
M_{\mathrm{AC}}=M_{0} \cos (\omega t-\delta)=\chi^{\prime} H_{0} \cos (\omega t)+\chi^{\prime \prime} H_{0} \sin (\omega t)
$$

determines the in-phase susceptibility $\chi^{\prime}=\left(M_{0} / H_{0}\right) \cos \delta$ and the out-of-phase component $\chi^{\prime \prime}=\left(M_{0} / H_{0}\right) \sin \delta$. At low frequencies $\omega=2 \pi f$, the delay $\delta$ is small so that the outof-phase component vanishes and the in-phase counterpart approaches the isothermal susceptibility when the magnetic subsystem is in a thermal equilibrium with the lattice subsystem as follows:

$$
\lim _{\omega \rightarrow 0} \widehat{\chi}=\left(\frac{\partial M_{\mathrm{AC}}}{\partial H}\right)_{T}=\chi_{T}
$$


With the increased frequency, the AC susceptibility reaches an opposite limit-adiabatic susceptibility:

$$
\lim _{\omega \rightarrow \infty} \widehat{\chi}=\left(\frac{\partial M_{\mathrm{AC}}}{\partial H}\right)_{S}=\chi_{S}
$$

when $\omega \tau \gg 1$ holds true and the magnetic subsystem is unable to exchange heat with the lattice subsystem and it conserves its entropy. Casimir-DuPré formula [28] connects the isothermal, adiabatic, and AC susceptibilities. After introducing the distribution parameter $\alpha$, this formula can easily be extended to the multiset form [29] as follows:

$$
\chi(\omega)=\chi_{S}+\sum_{k}^{K} \frac{\chi_{k}-\chi_{k-1}}{1+\left(\mathrm{i} \omega \tau_{k}\right)^{1-\alpha_{k}}}
$$

The in-phase and out-of-phase components can be written in closed forms which in the case of a two-set model are [29] as follows:

$$
\begin{gathered}
\chi^{\prime}(\omega)=\chi_{S}+\left(\chi_{T 1}-\chi_{S}\right) \frac{1+\left(\omega \tau_{1}\right)^{1-\alpha_{1}} \sin \left(\pi \alpha_{1} / 2\right)}{1+2\left(\omega \tau_{1}\right)^{1-\alpha_{1}} \sin \left(\pi \alpha_{1} / 2\right)+\left(\omega \tau_{1}\right)^{2-2 \alpha_{1}}} \\
+\left(\chi_{T 2}-\chi_{T 1}\right) \frac{1+\left(\omega \tau_{2}\right)^{1-\alpha_{2}} \sin \left(\pi \alpha_{2} / 2\right)}{1+2\left(\omega \tau_{2}\right)^{1-\alpha_{2}} \sin \left(\pi \alpha_{2} / 2\right)+\left(\omega \tau_{2}\right)^{2-2 \alpha_{2}}} \\
\chi^{\prime \prime}(\omega)=\left(\chi_{T 1}-\chi_{S}\right) \frac{\left(\omega \tau_{1}\right)^{1-\alpha_{1}} \cos \left(\pi \alpha_{1} / 2\right)}{1+2\left(\omega \tau_{1}\right)^{1-\alpha_{1}} \sin \left(\pi \alpha_{1} / 2\right)+\left(\omega \tau_{1}\right)^{2-2 \alpha_{1}}} \\
+\left(\chi_{T 2}-\chi_{T 1}\right) \frac{\left(\omega \tau_{2}\right)^{1-\alpha_{2}} \cos \left(\pi \alpha_{2} / 2\right)}{1+2\left(\omega \tau_{2}\right)^{1-\alpha_{2}} \sin \left(\pi \alpha_{2} / 2\right)+\left(\omega \tau_{2}\right)^{2-2 \alpha_{2}}}
\end{gathered}
$$

Here, the isothermal and adiabatic susceptibilities are constrained as $\chi_{S}<\chi_{T 1}<\chi_{T 2}$ in order to get positive contributions from each primitive component. The above formula can be rewritten using the mole fractions of the respective $k$-components $x_{k}$

$$
\chi(\omega)=\chi_{S}+\left(\chi_{T}-\chi_{S}\right)\left[\frac{x_{1}}{1+\left(\mathrm{i} \omega \tau_{1}\right)^{1-\alpha_{1}}}+\frac{x_{2}}{1+\left(\mathrm{i} \omega \tau_{2}\right)^{1-\alpha_{2}}}\right], x_{2}=1-x_{1}
$$

that fulfil $x_{1}=\left(\chi_{T 1}-\chi_{S}\right) /\left(\chi_{T}-\chi_{S}\right)$ and $x_{2}=\left(\chi_{T 2}-\chi_{T 1}\right) /\left(\chi_{T}-\chi_{S}\right)$.

A plot of $\chi^{\prime \prime} v s . \chi^{\prime}$ at the constant temperature refers to the Argand diagram (analogous to the Cole-Cole diagram for dielectrics). In an ideal case, it is a semicircle providing that there is a single relaxation time. The distribution parameter $\alpha$ causes its distortion to an arc. In the case of a two-set model two arcs are overlapping (Figure 4).

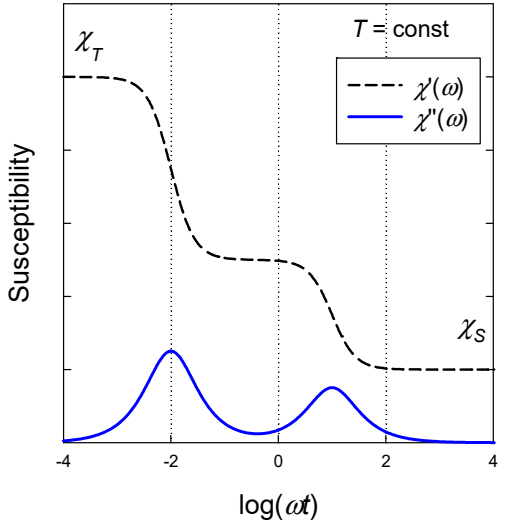

(a)

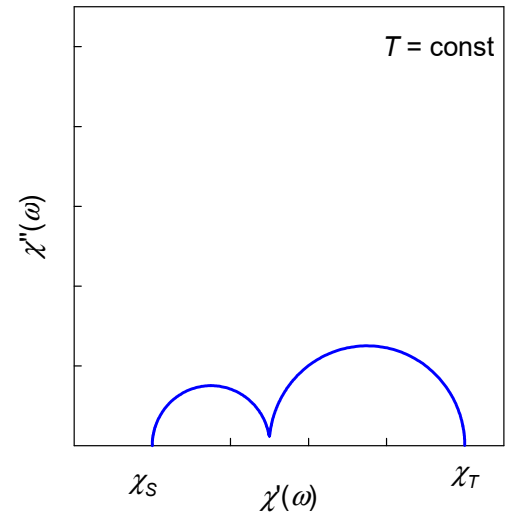

(b)

Figure 4. Frequency dependence of the AC susceptibility according to the two-set Debye model. (a) Envelope of AC susceptibility components. (b) Ideal Argand diagram $\left(\alpha_{1}=\alpha_{2}=0\right)$ with two overlapping semicircles. 


\section{Theoretical Part}

\subsection{Spin Hamiltonian}

The simplest theoretical model used in interpreting magnetic data (magnetization, DC-susceptibility, electron spin resonance) is based upon the spin-Hamiltonian formalism. This method utilizes a formal Hamiltonian containing the spin-only operators acting on the basis set of spin-only kets $\left|S, M_{S}\right\rangle$. One particular form refers to the zero-field splitting

$$
\begin{aligned}
\hat{H}_{k l}^{\text {zfs }}= & D\left(\hat{S}_{z}^{2}-\vec{S}^{2} / 3\right) \hbar^{-2}+E\left(\hat{S}_{x}^{2}-\hat{S}_{y}^{2}\right) \hbar^{-2} \\
& +\mu_{\mathrm{B}} B\left(g_{z} \hat{S}_{z} \cos \vartheta_{k}+g_{x} \hat{S}_{x} \sin \vartheta_{k} \cos \varphi_{l}+g_{y} \hat{S}_{y} \sin \vartheta_{k} \sin \varphi_{l}\right) \hbar^{-1}
\end{aligned}
$$

where the axial (rhombic) zero-field splitting parameters $D(E)$ occur. The Zeeman term involves the spin operators and the magnetic field oriented towards grids is uniformly distributed over a sphere ( $\vartheta$ and $\varphi$ are polar angles). Frequently, simplifications are applied, such as consideration of only Cartesian components. An ultimate demand is that the ground electronic term is non-degenerate (A- or B-type) and well separated from the excited electronic terms. For tetrahedral $\mathrm{Co}$ (II) with the ${ }^{4} \mathrm{~A}_{2}$ ground term, there are only four kets $|3 / 2, \pm 1 / 2\rangle$ and $|3 / 2, \pm 3 / 2\rangle$ forming two Kramers doublets [30].

\subsection{Griffith-Figgis Model}

The energy levels of hexacoordinate $\mathrm{Co}(\mathrm{II})$ complexes are derived from the octahedral mother term ${ }^{4} \mathrm{~T}_{1 \mathrm{~g}}$ that bears the non-zero orbital angular momentum $L$. The situation describes the spin-orbit Hamiltonian which works in the space of the spin- and orbital- kets $\left|L=1, M_{L}, S, M_{S}\right\rangle$ as outlined by Griffith and extended by Figgis (hereafter the GF model).

$$
\begin{aligned}
\hat{H}^{\mathrm{GF}}= & -(A \kappa \lambda)\left(\vec{L}_{\mathrm{p}} \cdot \vec{S}\right) \hbar^{-2}+\Delta_{\mathrm{ax}}\left(\hat{L}_{\mathrm{p}, z}^{2}-\vec{L}_{\mathrm{p}}^{2} / 3\right) \hbar^{-2}+\Delta_{\mathrm{rh}}\left(\hat{L}_{\mathrm{p}, x}^{2}-\hat{L}_{\mathrm{p}, y}^{2}\right) \hbar^{-2} \\
& +\mu_{\mathrm{B}} g_{\mathrm{e}}(\vec{B} \cdot \vec{S}) \hbar^{-1}-\mu_{\mathrm{B}}(A \kappa)\left(\vec{B} \cdot \vec{L}_{\mathrm{p}}\right) \hbar^{-1}
\end{aligned}
$$

The spin-orbit coupling involves the free-ion spin-orbit splitting parameter $\lambda=-\xi / 2 S$, the orbital and spin Zeeman terms, and the axial (rhombic) crystal-field splitting parameter $\Delta_{\mathrm{ax}}\left(\Delta_{\mathrm{rh}}\right)$. In addition, $\xi$ is the spin-orbit coupling constant and the other symbols are in their usual meaning. The remaining parameters involve the orbital reduction factor $\kappa$, and the Figgis CI parameter $A$. Due to the T-p isomorphism the orbital angular momentum is $L_{\mathrm{p}}=1$ and $g_{\mathrm{L}}=-1$. This Hamiltonian can be treated by a numerical procedure. For $\operatorname{Co}(\mathrm{II}), \lambda / h c=-155 \mathrm{~cm}^{-1}$ and the spin-orbit kets cover 12 multiplets forming six Kramers doublets belonging to the irreducible representations of the respective double group [30].

\subsection{Crystal Field Calculations}

The generalized crystal-field method is working in the complete set of kets generated by the $\mathrm{d}^{n}$ configuration (e.g., 120 for $\mathrm{Co}(\mathrm{II})$ ). By involving the electron repulsion, crystalfield potential, spin-orbit, orbital and spin Zeeman terms a detailed evaluation of the electronic levels (crystal-field multiplets and Zeeman levels) can be done in a short time. The internal parameters of the method are the crystal field poles $F_{4}(\mathrm{~L})$ and eventually $F_{2}(\mathrm{~L})$ for each ligand, the Racah parameters of the interelectron repulsion $B$ and $C$, and the spin-orbit coupling constant $\xi$. The crystal-field pole strength $F_{k}\left(R_{L}\right)=R_{L}^{-(k+1)}\left\langle r^{k}\right\rangle$ of $k$-th power for the ligand $\mathrm{L}$ situated at the distance $R_{\mathrm{L}}$ involves the momentum integral over the electronic variables $\left\langle r^{k}\right\rangle$. It relates to the common ligand field strength, e.g., $10 D q=(10 / 6) F_{4}\left(R_{L}\right)$ for an octahedral system. Consequently, the spin-Hamiltonian parameters $D, E, g_{z}, g_{x}, g_{y}, \chi_{\mathrm{TIP}}$ can be evaluated [31]. 


\subsection{Ab Initio Calculations}

Contemporary ab initio calculations start with the CASSCF module with inclusion of the relativistic effects followed by the NEVPT2 block that involves the spin-orbit interaction [32]. Spin-orbit corrected energy levels refer to the crystal-field multiplets and in the case of $\mathrm{Co}(\mathrm{II})$ systems to the set of Kramers doublets. The spin Hamiltonian parameters can be evaluated in the case of the orbitally non-degenerate ground electronic term. If the algorithm is applied to the case of the (quasi) degenerate ground term, the results can be false. Useful results can be obtained only by considering a large and flexible basis set for the involved atoms.

SH, GF, and ORCA/SO splitting are completely different tasks. For Co(II) systems, SH considers only two Kramers doublets arising from the ${ }^{4} \mathrm{~A}_{2}$ ground term split by $\delta$. GF considers six Kramers doublets arising from the ${ }^{4} \mathrm{~T}_{1 \mathrm{~g}}$ term on symmetry lowering (only in the case of the compressed tetragonal bipyramid $\delta$ is comparable with the $\mathrm{SH}$ value). Ab initio ORCA/SO calculations reproduce the complete energy spectrum and thus are superior.

\subsection{Fitting Procedures}

For temperature evolution of the molar magnetic susceptibility of Co(II) systems, some closed formulae can be found in the literature (see, for instance [30,31]). These, however, do not reproduce a correct powder average and they are missing for the field dependence of the magnetization.

Having energy levels at the disposal by the diagonalization of the model Hamiltonian in the given basis set, one can proceed by applying methods of statistical thermodynamics. For the given DC field, the partition function is formed $Z_{k l}(T, B)$ and its derivatives yield the magnetization $M_{k l}(T, B)$ and susceptibility $\chi_{k l}(T, B)$ referring to the grids of the magnetic field in Zeeman term. Then, an average produces the magnetic functions that match the powder nature of the sample.

Since the DC-susceptibility and DC-magnetization both reflect the same electronic structure of the sample, their fitting can be done simultaneously by minimizing a properly chosen error function. This is $F=w \cdot E(\chi)+(1-w) \cdot E(M)$ or $F=E(\chi) \cdot E(M)$ with the weight $w, E(\chi)$, and $E(M)$ representing the relative errors of the susceptibility and magnetization, respectively.

An analogous procedure can be utilized for a simultaneous fitting of the in-phase and out-of-phase components of the AC susceptibility: $F=w \cdot E\left(\chi^{\prime}\right)+(1-w) \cdot E\left(\chi^{\prime \prime}\right)$. Here, $E\left(\chi^{\prime}\right)$ and $E\left(\chi^{\prime \prime}\right)$ are relative errors of the components when using the one-set, two-set or three-set Debye model. Since there are simple closed formulas for them, no problem is found to apply several hundred-thousand searches for advanced non-linear optimization algorithms such as genetic algorithms.

The primitive functions of the Debye model possess a useful property: The peak of $\chi^{\prime \prime}$ is perfectly symmetric with respect to $\log f$. Figure 5 visualizes a test of the stability of the fitting procedure when the experimental points are reduced from the right side-high frequencies. An omission of 1 through 7 data points has a negligible effect to the fitted set of seven parameters even in the difficult case when the LF channel appears as a shoulder. The graph is a superposition of eight lines, each fitted independently. This finding approves the determination of the relaxation parameters even in the case when the data taking is stopped (not allowed by the hardware, e.g., $f<1500 \mathrm{~Hz}$ ) before reaching the peak maximum. However, one has carefully checked the standard deviations of the parameters and eventually their pair-correlation (see Supplementary Information). The advantage of the fitting procedure lies in the fact that it can separate the primitive components also in the case of their overlap (resulting in a shoulder). 

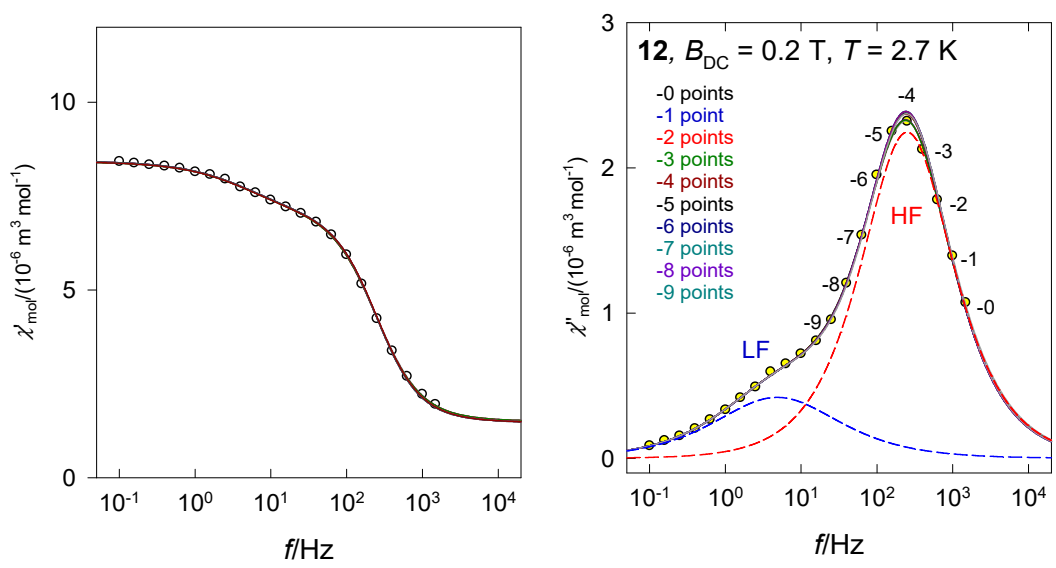

Figure 5. Test of the stability of the fitted relaxation time when 1 to 9 data points from the HF range are gradually omitted. Solid lines for individual fits are overlapped. Dashed lines: Primitive lowfrequency (LF) and high-frequency (HF) components. Data adapted from ref. [33] for [Co(biq) $\left.\mathrm{Cl}_{2}\right], 12$. 2015, Royal Society of Chemistry.

\section{Data Analysis}

\subsection{Magnetic Data}

For a series of tetra-, penta-, and hexacoordinate $\mathrm{Co}(\mathrm{II})$ complexes, the values of the axial zero-field splitting parameter $D$ extracted from the magnetic data are listed in Table 2 along with available $a b$ initio data using the CASSCF + NEVTP2 method (ORCA package). The high-frequency/high-field EPR data are also quoted when available.

Table 2. Comparison of selected Co(II) complexes showing SMR.

\begin{tabular}{|c|c|c|c|c|c|c|c|c|}
\hline Complex & No. & SMR $^{a}$ & RTB $^{b}$ & Channels $^{c}$ & $J^{\mathrm{d}}$ & $D(\mathrm{MS} \& \mathrm{M}){ }^{\mathrm{e}}$ & $D(A b \text { Initio })^{\mathrm{e}}$ & Ref. \\
\hline \multicolumn{9}{|l|}{ Hexa-coordination } \\
\hline$[\mathrm{Co}(p y d c a)(d m p y)] \cdot 0.5 \mathrm{H}_{2} \mathrm{O}$ & 2 & Y & Y & 3 & & 55 & $\begin{array}{l}(-67.2) \\
(-121)\end{array}$ & {$[26]$} \\
\hline$\left[\mathrm{Co}(b z p y)_{4} \mathrm{Cl}_{2}\right]$ & 5 & $\mathrm{Y}$ & Y & 3 & & 106 & $\begin{array}{l}88.6 \\
124\end{array}$ & [34] \\
\hline$\left[\mathrm{Co}(b z p y)_{4}(\mathrm{NCS})_{2}\right]$ & 6 & $\mathrm{Y}$ & Y & 2 & & 90.5 & $\begin{array}{l}88.6 \\
90.8\end{array}$ & {$[34]$} \\
\hline $\begin{array}{l}{\left[\mathrm{Co}^{\mathrm{III}} \mathrm{Co}^{\mathrm{II}}\left(\mathrm{H}_{2} \mathrm{~L}\right)_{2}(a c)\left(\mathrm{H}_{2} \mathrm{O}\right)\right]} \\
\left(\mathrm{H}_{2} \mathrm{O}\right)_{3}\end{array}$ & 7 & $\mathrm{Y}$ & Y & 2 & & (145) & $(-99.6)$ & {$[35]$} \\
\hline$\left[\mathrm{Co}(d m p y)_{2}\right](d n b z)_{2}$ & & $\mathrm{Y}$ & & 3 & & $(43.6)$ & $(-94.8)$ & [27] \\
\hline$\left[\mathrm{Co}\left(\mathrm{dppm}^{\mathrm{O}, \mathrm{O}}\right)_{3}\right]\left[\mathrm{Co}(\mathrm{NCS})_{4}\right]$ & & $\mathrm{N}$ & - & - & & $\mathrm{O} 83, \mathrm{~T}-5.0$ & $\mathrm{O} 102, \mathrm{~T}-3.5$ & [36] \\
\hline$\left[\mathrm{Co}\left(\mathrm{dppm}^{\mathrm{O}, \mathrm{O}}\right)_{3}\right]\left[\mathrm{CoCl}_{4}\right]$ & & $\mathrm{Y}$ & $\mathrm{N}$ & 2 & & O 77, T 4.6 & $\mathrm{O} 157, \mathrm{~T}-1.9$ & [36] \\
\hline$\left[\mathrm{Co}\left(\mathrm{dppm}^{\mathrm{O}, \mathrm{O}}\right)_{3}\right]\left[\mathrm{CoBr}_{4}\right]$ & & Y & $\mathrm{N}$ & 2 & & O 122, T 15.0 & $\mathrm{O} 129, \mathrm{~T}-2.5, \mathrm{~T} 6.6$ & {$[36,37]$} \\
\hline$\left[\mathrm{Co}\left(\mathrm{dppm}^{\mathrm{O}, \mathrm{O}}\right)_{3}\right]\left[\mathrm{CoI}_{4}\right]$ & & Y & $\mathrm{N}$ & 2 & & O 99, Т 19.3 & O $107, \mathrm{~T} 14.9$ & [36] \\
\hline \multicolumn{9}{|l|}{ Penta-coordination } \\
\hline$\left[\mathrm{Co}\left(\mathrm{Me}_{6}\right.\right.$ tren $\left.) \mathrm{Cl}\right] \mathrm{ClO}_{4}, \operatorname{sim}$ & & $\mathbf{Y}$ & & 2 & & $-4.9,-6.2$ & -9.73 , epr -8.12 & {$[38,39]$} \\
\hline$\left[\mathrm{Co}\left(\mathrm{Me}_{6}\right.\right.$ tren $\left.) \mathrm{Br}\right] \mathrm{Br}$ & & $\mathrm{Y}$ & & na & & -2.5 & -2.12 , epr -2.40 & [39] \\
\hline$\left[\mathrm{Co}(\right.$ bzimpy $\left.) \mathrm{Cl}_{2}\right] \cdot \mathrm{DMF}$ & 8 & $\mathrm{Y}$ & & 2 & & 58.4 & $(-87)$ & [40] \\
\hline$\left[\mathrm{Co}(\right.$ bzimpy $\left.) \mathrm{Br}_{2}\right] \cdot \mathrm{DMF}$ & 9 & $\mathrm{Y}$ & $\mathrm{Y}$ & 2 & & 47.0 & 63.7 & [40] \\
\hline$\left[\mathrm{Co}(\right.$ bzimpy $\left.) \mathrm{I}_{2}\right]$ & & $\mathrm{Y}$ & & 2 & & 40.0 & & [40] \\
\hline$\left[\mathrm{Co}\left(\mathrm{L}^{\mathrm{I}}\right) \mathrm{Cl}_{2}\right]$ & & $\mathrm{Y}$ & & 2 & & 61.9 & $(-62)$ & [41] \\
\hline$\left[\mathrm{Co}\left(\mathrm{L}^{\mathrm{C}} 7\right) \mathrm{Cl}_{2}\right]$ & & $\mathrm{Y}$ & & 2 & 1.54 & 153 & $(-119)$ & [41] \\
\hline$\left[\mathrm{Co}\left(\mathrm{L}^{\mathrm{C} 10}\right) \mathrm{Cl}_{2}\right]$ & & $\mathrm{Y}$ & & 2 & 1.42 & 70.1 & 44.2 & [41] \\
\hline$\left[\mathrm{Co}\left(\mathrm{L}^{\mathrm{C} 12}\right) \mathrm{Cl}_{2}\right]$ & & $\mathrm{Y}$ & & 2 & & 46.8 & 43.4 & [41] \\
\hline$\left[\mathrm{Co}\left(\mathrm{L}^{\mathrm{C} 14}\right) \mathrm{Cl}_{2}\right]$ & & Y & & 2 & 1.06 & 87.5 & $(-58)$ & {$[41]$} \\
\hline $\begin{array}{l}{\left[\left(\mathrm{N}_{3}\right)_{2} \mathrm{Co}^{\mathrm{III}}(\mathrm{L})(\mu-\right.} \\
\left.\left.\mathrm{N}_{3}\right) \mathrm{Co}^{\mathrm{II}}\left(\mathrm{N}_{3}\right)\right] \cdot 2 \mathrm{MeOH} \\
\text { Tetra-coordination }\end{array}$ & & $\mathrm{Y}$ & & 2 & & 38.7 & 42.4 & {$[42]$} \\
\hline$\left[\mathrm{Co}\left(\mathrm{PPh}_{3}\right)_{2}(\mathrm{NCS})_{2}\right]$ & & Y & & 2 & & -9.44 & -12.2 & [43] \\
\hline$\left[\mathrm{Co}(\right.$ DPEphos $\left.) \mathrm{Cl}_{2}\right]$ & & $\mathrm{Y}$ & & 1 & & & -14.4 & [44] \\
\hline$\left[\mathrm{Co}(\right.$ Xantphos $\left.) \mathrm{Cl}_{2}\right]$ & & $\mathrm{Y}$ & & 1 & & & -15.4 & [44] \\
\hline$\left[\mathrm{Co}\left(\mathrm{PPh}_{3}\right)_{2} \mathrm{Cl}_{2}\right]$ & & Y & & $1(2)$ & & -11.6 & -16.2, epr -14.8 & {$[44-46]$} \\
\hline$\left[\mathrm{Co}\left(\mathrm{PPh}_{3}\right)_{2} \mathrm{Br}_{2}\right]$ & 10 & $\mathbf{Y}$ & Y & 2 & & -12.5 & & {$[47]$} \\
\hline
\end{tabular}


Table 2. Cont.

\begin{tabular}{|c|c|c|c|c|c|c|c|c|}
\hline Complex & No. & $\mathrm{SMR}^{\mathrm{a}}$ & RTB $^{b}$ & Channels $^{c}$ & $J^{\mathrm{d}}$ & $D(\mathrm{MS} \& M)^{\mathrm{e}}$ & $D\left(A b\right.$ Initio $^{\mathrm{e}}$ & Ref. \\
\hline$\left[\mathrm{Co}\left(\mathrm{PPh}_{3}\right)_{2} \mathrm{I}_{2}\right]$ & & $\mathrm{Y}$ & & 1 & & -36.9 & & [48] \\
\hline$\left[\mathrm{Co}\left(\mathrm{AsPh}_{3}\right)_{2} \mathrm{I}_{2}\right]$ & & $\mathrm{Y}$ & & 1 & & -74.7 & & [48] \\
\hline$\left[\mathrm{Co}(q u)_{2} \mathrm{I}_{2}\right]$ & & $\mathrm{N}$ & & - & & 9.2 & & [48] \\
\hline$\left[\mathrm{Co}(b c p) \mathrm{Cl}_{2}\right]$ & & Y & & 1 & 0.24 & -6.62 & & [49] \\
\hline$\left[\mathrm{Co}(b c p) \mathrm{Br}_{2}\right]$ & & $\mathrm{N}$ & & - & -0.023 & -6.72 & & [49] \\
\hline$\left[\mathrm{Co}(b c p) \mathrm{I}_{2}\right]$ & & $\mathrm{N}$ & & - & -0.63 & -7.03 & & [49] \\
\hline$\left[\mathrm{Co}(\right.$ dmphen $\left.) \mathrm{Br}_{2}\right]$ & & $\mathrm{Y}$ & & 2 & & 10.6 & epr 11.7 & [50] \\
\hline$\left[\mathrm{Co}(\right.$ dmphen $\left.) \mathrm{Cl}_{2}\right]$ & & $\mathrm{N}$ & & - & -1.00 & 11.9 & 15.6 & [51] \\
\hline$\left[\mathrm{Co}(\right.$ dmphen $\left.) \mathrm{Br}_{2}\right]$ & & $\mathrm{N}$ & & 2,3 & & 13.8 & 13.8 & [51] \\
\hline$\left[\mathrm{Co}(\right.$ dmphen $\left.) \mathrm{I}_{2}\right]$ & & $\mathrm{Y}$ & & 2,3 & & 16.6 & 11.4 & [51] \\
\hline$\left[\mathrm{Co}(\right.$ biq $\left.) \mathrm{Cl}_{2}\right]$ & 11 & $\mathrm{Y}$ & Y & 2 & & 10.5 & 16.1 & [33] \\
\hline$\left[\mathrm{Co}(\right.$ biq $\left.) \mathrm{Br}_{2}\right]$ & & $\mathrm{Y}$ & & 2 & & 12.5 & 14.7 & [33] \\
\hline$\left[\mathrm{Co}(\right.$ biq $\left.) \mathrm{I}_{2}\right]$ & & $\mathrm{Y}$ & & 2 & & 10.3 & 13.7 & [33] \\
\hline
\end{tabular}

a SMR — slow magnetic relaxation. Bold-true single ion magnets in the zero field. ${ }^{\mathrm{b}}$ RTB-reciprocating thermal behavior. Blank field means that the reciprocating thermal behavior has not been detected in the applied DC fields. ${ }^{\mathrm{C}}$ Number of relaxation channels (modes) in the applied DC field. ${ }^{\mathrm{d}} J$-isotropic exchange coupling constants in $\mathrm{cm}^{-1}$ conforming convention $-J$ in the spin Hamiltonian. ${ }^{\mathrm{e}} \mathrm{D}(\mathrm{MS} \& \mathrm{M})$ axial zero-field splitting parameter extracted from the magnetic susceptibility and magnetization; $D($ ab initio) from calculations, eventually from epr (electron paramagnetic resonance) in units of $\mathrm{cm}^{-1}$. Values in brackets could be false due to the orbitally (quasi) degenerate electronic ground term and a divergence of the perturbation theory.

For tetracoordinate $\mathrm{Co}(\mathrm{II})$ complexes, in geometry of a compressed and also elongated bisphenoid, the ground electronic term is orbitally nondegenerate ${ }^{4} \mathrm{~A}_{2}$ (Figure 6). This justifies an application of the spin Hamiltonian formalism and the experimental data on $D$ reasonably match theoretical predictions. The majority of these systems exhibit slow magnetic relaxation (SMR) with 1, 2 or 3 relaxation channels irrespective of the sign of the $D$-parameter (Orbach relaxation mechanism requires negative $D$ values). In certain cases, however, the exchange interaction of the antiferromagnetic nature prevents the observation of SMR.

For the hexacoordinate Co(II) system the electronic terms are daughters of the octahedral ${ }^{4} \mathrm{~T}_{1 \mathrm{~g}}$ that is orbitally triply degenerate. On a tetragonal compression the daughter ground term is orbitally non-degenerate ${ }^{4} \mathrm{~A}_{1 \mathrm{~g}}$ for which the spin-Hamiltonian formalism is legitimate to apply. The $D$-parameter adopts high positive values, $D / h c \sim 100 \mathrm{~cm}^{-1}$, and separates two Kramers doublets $[30,31]$. The positive $D$-value discriminates the presence of the Orbach mechanism since now the barrier to spin reversal, requiring $D<0$, does not exist.

On a tetragonal elongation the ground daughter term stays doubly degenerate ${ }^{4} \mathrm{E}_{\mathrm{g}}$ and the spin-Hamiltonian formalism cannot be applied. Eight magnetic levels forming four Kramers doublets are in the play. Consequently, the D-parameter is undefined. When the ab initio calculations of the spin-Hamiltonian parameters are, as program options, activated, the results could be false (e.g., $D<0, g_{z}<2$ ). Moreover, in the case of quasi degeneracy the $\mathrm{ab}$ initio predictions could fail due to the divergence of the perturbation theory. The same obstacles hold true for the pentacoordinate Co(II) complexes in the geometry of the square pyramid.

A few complexes reviewed in Table 2, in addition to the SMR (SIM) behavior, show the reciprocating thermal behavior (RTB) referring to the high-frequency channel of the slow magnetic relaxation. These are collected in Table 3 along with fitted parameters that reproduce a temperature development of the high-frequency relaxation time using a simple equation $\tau^{-1}=G T^{l}+F T^{-k}$. There is one obstacle: When the parameters $G$ and $l$ ( $F$ and $k$ ) are allowed to float, they could be mutually dependent: With the increasing $G$ the parameter $l$ decreases and vice versa. This may have a minor influence for the interpolated data, but sometimes brings a wrong prediction in extrapolation. Therefore, also the correlation coefficients $\rho(G, l)$ and $\rho(F, k)$ need be monitored. 
$\mathbf{D}_{2 \mathrm{~d}}$, prolate bisphenoid /elongated

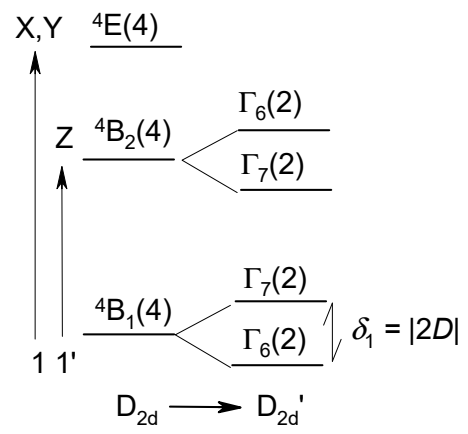

$\mathrm{D}_{3 \mathrm{~h}}$, trigonal bipyramid

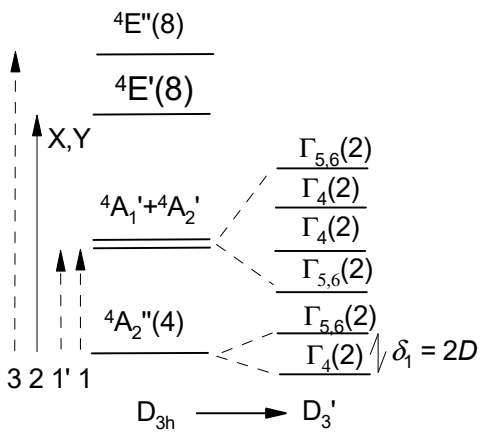

D4h, compressed bipyramid

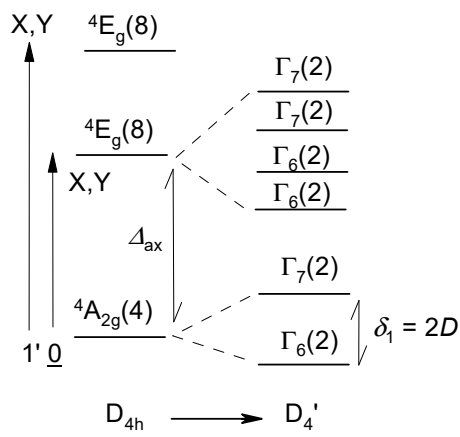

$\mathbf{D}_{2 \mathrm{~d}}$, oblate bispheniod /compressed

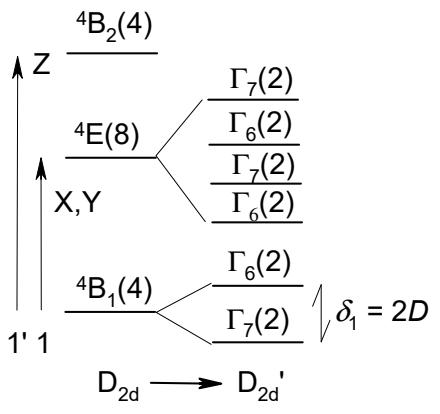

$\mathrm{C}_{4 \mathrm{v}}$, square pyramid

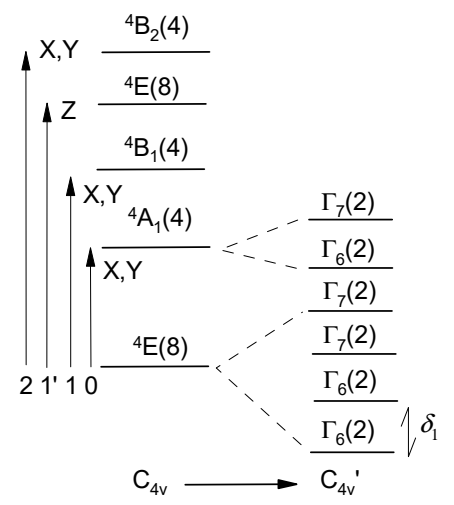

D4h, elongated bipyramid

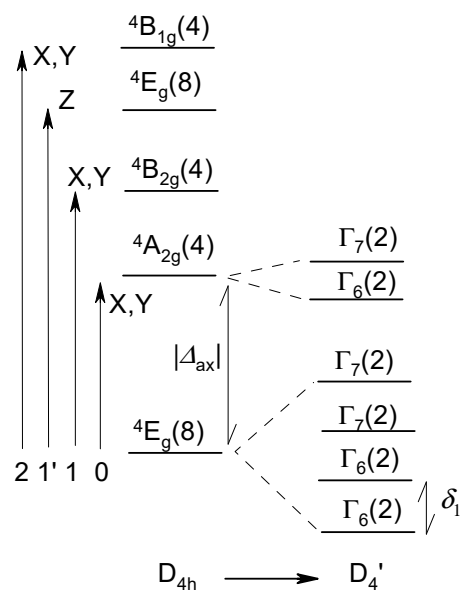

Figure 6. Energy level diagrams for high-spin Co(II) complexes. Crystal field terms are labelled according to the Mulliken notation (A, B, E), the crystal field multiplets according to Bethe $\left(\Gamma_{i}\right)$ as irreducible representations of the double group.

The extensive graphs reported below show the experimental points of the out-of-phase susceptibility as a function of the frequency of the oscillating magnetic field and/or applied DC field. The high-temperature tail of the data was analyzed by employing the linear regime for the $\ln \tau$ vs. $T^{-1}$ dependence written as $\ln \tau=b[0]+b[1] \cdot T^{-1}$. The tangential $b[1]$ refers not necessarily to the Orbach process (effective barrier to the spin reversal) since the possible limits are in the data taking/analysis. The intermediate/low temperature regime was analyzed using the $\ln \tau$ vs. $\ln T$ function (see Figure 1). 
Table 3. Characteristics of the reciprocating thermal behavior for high-frequency channel of slow magnetic relaxation in transition metal complexes ${ }^{\text {a }}$.

\begin{tabular}{|c|c|c|c|c|c|c|c|}
\hline No. & Chromophore & $B_{\mathrm{DC}} / \mathrm{T}$ & $\begin{array}{l}G / \mathbf{K}^{-l} \mathbf{s}^{-1} \\
C / \mathbf{K}^{-n} \mathbf{s}^{-1}\end{array}$ & $l$ or $n$ & $F / K^{k} \mathbf{s}^{-1}$ & $k$ & Ref. \\
\hline $1\left[\mathrm{Mn}(b z p y)_{4} \mathrm{Cl}_{2}\right]$ & $\mathrm{MnN}_{4} \mathrm{Cl}_{2}$ & 0.35 & $57(13)$ & $2.20(10)$ & $20.1(2)$ & $1.98(12)$ & {$[52]$} \\
\hline $2[\mathrm{Co}(p y d c a)(d m p y)] \cdot 0.5 \mathrm{H}_{2} \mathrm{O}$ & $\mathrm{CoN}_{2} \mathrm{O}_{4}$ & 0.40 & $0.13(1)$ & $5.93(4)$ & $3.7(1) \times 10^{3}$ & $0.78(3)$ & [26] \\
\hline \multirow{2}{*}{$3[\mathrm{Cu}(p y d c a)(d m p y)] \cdot 0.5 \mathrm{H}_{2} \mathrm{O}$} & $\mathrm{CuN}_{2} \mathrm{O}_{4}$ & 0.5 & $46(13)$ & $1.9(1)$ & $2.5(4) \times 10^{3}$ & $0.73(18)$ & [53] \\
\hline & & 1.0 & $5.6(42)$ & $2.6(3)$ & $4.2(6) \times 10^{3}$ & $0.79(17)$ & \\
\hline \multirow[t]{2}{*}{$4[\mathrm{Ni}(p y d c a)(d m p y)] \cdot \mathrm{H}_{2} \mathrm{O}$} & $\mathrm{NiN}_{2} \mathrm{O}_{4}$ & 0.4 & $10.3(2)$ & 4.7 & $3.4(1) \times 10^{3}$ & 0.58 & [54] \\
\hline & & 0.6 & $6.4(3)$ & 4.76 & $8.0(3) \times 10^{3}$ & 0.84 & \\
\hline \multirow[t]{2}{*}{$5\left[\mathrm{Co}(b z p y)_{4} \mathrm{Cl}_{2}\right]$} & $\mathrm{CoN}_{4} \mathrm{Cl}_{4}$ & 0.4 & $19(5)$ & $4.17(16)$ & $5.1(7) \times 10^{3}$ & $0.63(19)$ & [34] \\
\hline & & 0.6 & $68(19)$ & $3.66(18)$ & $40.9(17) \times 10^{3}$ & $1.22(7)$ & \\
\hline $6\left[\mathrm{Co}(b z p y)_{4}(\mathrm{NCS})_{2}\right]$ & $\mathrm{CoN}_{4} \mathrm{~N}_{2}$ & 0.4 & $18(5)$ & $4.26(14)$ & $4.3(6) \times 10^{3}$ & $0.42(22)$ & [34] \\
\hline $7\left[\mathrm{Co}^{\mathrm{III}} \mathrm{Co}^{\mathrm{II}}\left(\mathrm{LH}_{2}\right)_{2}(a c)\left(\mathrm{H}_{2} \mathrm{O}\right)\right]\left(\mathrm{H}_{2} \mathrm{O}\right)_{3}$ & $\mathrm{CoO}_{4} \mathrm{OO}$ & 0.4 & 33(9) & $4.10(14)$ & $9.1(12) \times 10^{3}$ & $0.75(19)$ & [35] \\
\hline $8\left[\mathrm{Co}(\right.$ bzimpy $\left.) \mathrm{Cl}_{2}\right] \cdot \mathrm{DMF}$ & $\mathrm{CoN}_{3} \mathrm{Cl}_{2}$ & 0.4 & $3.4(8)$ & $5.36(14)$ & $7.3(1) \times 10^{3}$ & {$[0]$} & {$[40]$} \\
\hline \multirow[t]{2}{*}{$9\left[\mathrm{Co}(\right.$ bzimpy $\left.) \mathrm{Br}_{2}\right] \cdot \mathrm{DMF}$} & $\mathrm{CoN}_{3} \mathrm{Br}_{2}$ & 0.2 & $48(19)$ & $4.00(25)$ & $10.2(12) \times 10^{3}$ & $0.75(21)$ & [40] \\
\hline & $\mathrm{CoN}_{3} \mathrm{Br}_{2}$ & 0.4 & $12.1(45)$ & $5.08(24)$ & $28(1) \times 10^{3}$ & $0.56(6)$ & \\
\hline $10\left[\mathrm{Co}\left(\mathrm{PPh}_{3}\right)_{2} \mathrm{Br}_{2}\right]$ & $\mathrm{CoP}_{2} \mathrm{Br}_{2}$ & 0.2 & $0.098(82)$ & $12.4(8)$ & $67(18)$ & $2.53(41)$ & [47] \\
\hline $11\left[\mathrm{Co}(\mathrm{biq}) \mathrm{Cl}_{2}\right]$ & $\mathrm{CoN}_{2} \mathrm{Cl}_{2}$ & 0.3 & $0.0083(17)$ & $12.0(2)$ & $2.3(4) \times 10^{3}$ & $1.0(3)$ & [33] \\
\hline
\end{tabular}

a Equation $\tau^{-1}=G T^{l}+F T^{-k}$ or $\tau^{-1}=C T^{n}+F T^{-k}$. Standard deviations in parentheses. Resulting parameters of the non-linear fitting for the whole temperature range can be slightly different from those referring to the linear fits to a limited temperature point.

\subsection{Example of Reciprocating Thermal Behavior}

The hexacoordinate complex [ $\left.\mathrm{Mn}^{\mathrm{II}}(b z p y)_{4} \mathrm{Cl}_{2}\right]$, hereafter 1, belongs to the class of SIMs showing RTB [52]. This $S=5 / 2$ spin system with ${ }^{6} \mathrm{~A}_{1 \mathrm{~g}}$ ground electronic term possesses a very low (rather negligible) $D$-parameter as verified by the $D C$ magnetic data and $a b$ initio calculations: $D / h c=-0.63 \mathrm{~cm}^{-1}$. A small $D$-value is also indicated by simulation of the X-band EPR spectra. Such a D-value discriminates the presence of the Orbach relaxation mechanism.

The first scan of the AC susceptibility refers to a field dependence of the AC response at $T=2.0 \mathrm{~K}$ for a set of four trial frequencies $f$ of the oscillating field (Figure $7 \mathrm{~b}$ ). It can be seen that the low-frequency $\chi^{\prime \prime}$ differs substantially from the rest of the frequencies. It passes through a marked maximum at $B_{\mathrm{DC}}=0.35 \mathrm{~T}$. Thus, a traditional selection of a small field $B_{\mathrm{DC}}=0.1$ is less informative.

The second scan has been done at the selected $B_{\mathrm{DC}}=0.35 \mathrm{~T}$ for a set of 22 frequencies ranging between $f=0.1$ to $1500 \mathrm{~Hz}$ and temperature rising from $T=1.9$ to $10 \mathrm{~K}$. The $\mathrm{AC}$ susceptibility for 1 confirms the slow magnetic relaxation with three relaxation channels: Low-frequency (LF), intermediate-frequency (IF), and high-frequency(HF), see Figure 7a. At $B_{\mathrm{DC}}=0.35$ and low temperature, the LF relaxation channel dominates and escapes more rapidly on heating than the HF one. The HF channel borrows its intensity (isothermal susceptibility) from IF and LF until a maximum and then escapes in a usual way. At $T=1.9 \mathrm{~K}$, the relaxation time is as long as $\chi(\mathrm{LF})=798 \mathrm{~ms}$ and the mole fraction of the slowly relaxing species is $x(\mathrm{LF})=0.49$. It is interesting to note that the situation around $f=40 \mathrm{~Hz}$ resembles the isosbestic point for a unimolecular reaction $\{\mathrm{LF}+\mathrm{IF}\} \leftrightarrow \mathrm{HF}$.

The molar AC susceptibility was subjected to the fitting procedure by employing the three-set (two- or single-set) Debye model. The obtained relaxation times are presented in Table 4 along with the R-factors (discrepancy factors) for the absorption and dispersion, each parameter is presented with its standard deviation.

For the fitted set of parameters, the interpolation/extrapolation lines have been generated (they consist of three primitive functions in the case of the three-set Debye model), which are drawn in Figure 7 as solid lines. A detailed inspection confirms that the convoluted lines pass through the experimental data perfectly. Notice, each primitive line is mirror-symmetric in the $\log f$ scale so that even the reduced data set is fully informative when reaching the maximum of the peak (when the maximum of the HF-peak is not approached, the fitted data show increasing standard deviations and they should be considered with care). 


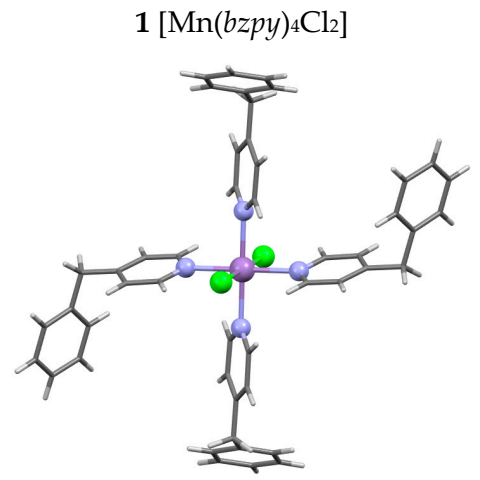

CCDC No 1849019

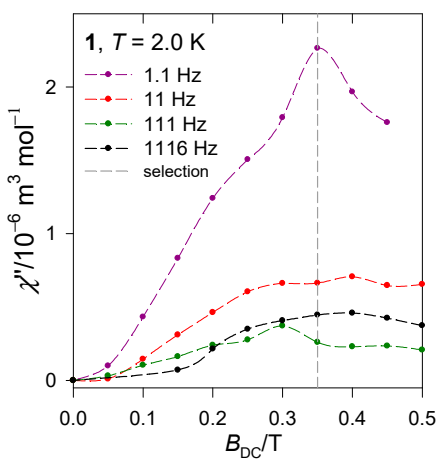

(b)
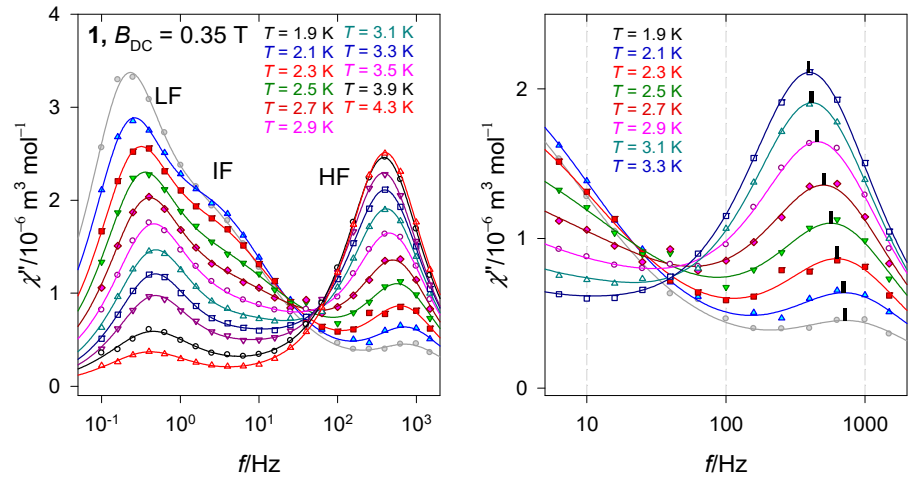

(a)

continued
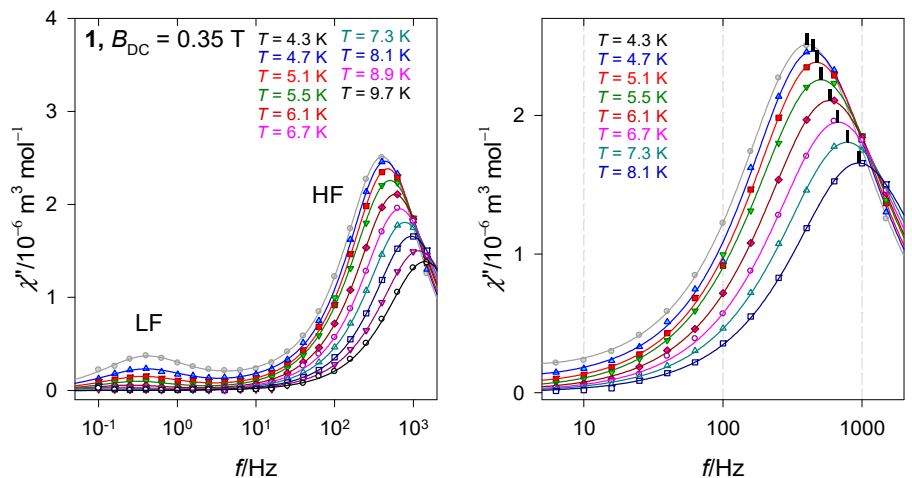

Figure 7. Frequency dependence of the out-of-phase susceptibility at various temperatures and external fields for $\left[\mathrm{Mn}(\text { bzpy })_{4} \mathrm{Cl}_{2}\right]$. (a) Left-full scale of data taking, right-zoomed high-frequency range truncated for clarity. Solid lines-fitted. (b) field dependence. Vertical mark envisages the maximum on $\chi^{\prime \prime}$; notice its movement on heating to a slower relaxation and then back to the faster one. Data adapted from ref. [52]. 2019, American Chemical Society.

Table 4. Fitted relaxation times of the Debye model for $\left[\mathrm{Mn}(b z p y)_{4} \mathrm{Cl}_{2}\right]$.

\begin{tabular}{cccccccc}
\hline $\boldsymbol{T} / \mathbf{K}$ & $\boldsymbol{R}\left(\chi^{\prime}\right) / \%$ & $\boldsymbol{R}\left(\chi^{\prime \prime}\right) / \%$ & $\boldsymbol{\tau}_{\mathbf{L F}} / \mathbf{s}$ & $\boldsymbol{\tau}_{\mathbf{I F}} / \mathbf{1 0}^{-\mathbf{3}} \mathbf{s}$ & $\boldsymbol{\tau}_{\mathbf{H F}} / \mathbf{1 0} \mathbf{0}^{-\mathbf{6}} \mathbf{s}$ & $x_{\mathbf{L F}}$ & $x_{\mathbf{H F}}$ \\
\hline 1.9 & 0.46 & 1.9 & $0.798(32$ & $60(15)$ & $\mathbf{1 8 3 ( 3 7 )}$ & 0.49 & 0.07 \\
2.1 & 0.28 & 1.3 & $0.738(22)$ & $54(6)$ & $\mathbf{1 9 8 ( 1 5 )}$ & 0.42 & 0.10 \\
2.3 & 0.35 & 1.7 & $0.612(26)$ & $48(9)$ & $\mathbf{2 2 9 ( 1 3 )}$ & 0.38 & 0.15 \\
2.5 & 0.43 & 2.4 & $0.533(27)$ & $42(20)$ & $\mathbf{2 5 2 ( 1 4 )}$ & 0.34 & 0.19 \\
2.7 & 0.78 & 2.4 & $0.456(35)$ & $33(39)$ & $\mathbf{2 8 9 ( 2 2 )}$ & 0.32 & 0.25 \\
2.9 & 0.38 & 1.9 & $0.389(14)$ & $27(26)$ & $\mathbf{3 2 8 ( 9 )}$ & 0.30 & 0.32 \\
3.1 & 0.29 & 1.6 & $0.360(17)$ & $18(5)$ & $\mathbf{3 6 8 ( 8 )}$ & 0.34 & 0.45 \\
3.3 & 0.26 & 1.3 & $0.363(16)$ & $18(6)$ & $\mathbf{3 8 8}(7)$ & 0.27 & 0.53 \\
3.5 & 0.18 & 1.3 & $0.357(15)$ & $19(6)$ & $\mathbf{4 0 9 ( 5 )}$ & 0.24 & 0.61 \\
3.9 & 0.29 & 1.4 & $0.381(34)$ & $9(12)$ & $404(5)$ & 0.18 & 0.71 \\
4.3 & 0.23 & 0.98 & $0.410(44)$ & $9(9)$ & $392(5)$ & 0.13 & 0.81 \\
4.7 & 0.35 & 3.1 & $0.416(80)$ & $9(9)$ & $362(6)$ & 0.09 & 0.89 \\
5.1 & 0.34 & 1.7 & $0.451(90)$ & 9 & $338(4)$ & 0.06 & 0.93 \\
5.5 & 0.41 & 2.3 & $0.521(147)$ & - & $315(4)$ & 0.04 & 0.96 \\
6.1 & 0.14 & 0.74 & $0.635(111)$ & & $273(1)$ & 0.03 & 0.97 \\
6.7 & 0.20 & 1.4 & $0.867(402)$ & & $237(2)$ & 0.02 & 0.98 \\
7.3 & 0.16 & 0.99 & $1.086(593)$ & & $204(1)$ & 0.01 & 0.99 \\
8.1 & 0.24 & 1.7 & - & & $168(2)$ & - & 1 \\
8.9 & 0.39 & 2.2 & & & $136(3)$ & & 1 \\
9.7 & 0.35 & 1.9 & & & $113(2)$ & & 1 \\
\hline
\end{tabular}

Mole fractions: $x_{\mathrm{LF}}=\left(\chi_{T, \mathrm{LF}}-\chi_{S}\right) /\left(\chi_{T}-\chi_{S}\right), x_{\mathrm{IF}}=\left(\chi_{T, \mathrm{IF}}-\chi_{T, \mathrm{LF}}\right) /\left(\chi_{T}-\chi_{S}\right), x_{\mathrm{HF}}=\left(\chi_{T, \mathrm{HF}}-\chi_{T, \mathrm{IF}}\right) /\left(\chi_{T}-\chi_{S}\right)$, $\chi_{T, \mathrm{HF}}=\chi_{T}$, and $x_{\mathrm{LF}}+\chi_{\mathrm{IF}}+\chi_{\mathrm{HF}}=1$. SI unit for the molar magnetic susceptibility $\left[10^{-6} \mathrm{~m}^{3} \mathrm{~mol}^{-1}\right]$. Standard deviations in parentheses (last digit). $R$-discrepancy factor of the fit for dispersion $\chi^{\prime}$ and absorption $\chi^{\prime \prime}$, respectively. Bold data refer to RTB. 
In Figure 7, a vertical mark at the top of the convoluted curve envisages the maximum on $\chi^{\prime \prime}$ that determines the relaxation time $\tau_{\mathrm{HF}}$. Notice its movement on heating to a slower relaxation and then back to the faster one, which is the reciprocating thermal behavior. RTB is also well seen in Figure 8 where several presentations of the temperature evolution of the high-frequency relaxation time are drawn. A traditional Arrhenius-like plot $\ln \tau$ vs. $T^{-1}$ (Figure 8a) would predict the barrier to spin reversal $U_{\text {eff }} / k_{\mathrm{B}}=19 \mathrm{~K}$ when the Orbach mechanism is considered, which is in strong contrast with the negligible D-value. This high-temperature tail is recovered by the straight line in $\ln \tau$ vs. $\ln T$ graph (Figure $8 b$ ). The temperature exponent in $\tau^{-1}(\mathrm{HT})=G T^{l}, l \sim 2.2$, indicates that the phonon bottleneck mechanism applies rather than the Raman relaxation mechanism for which the temperature exponent close to 5 is expected (in the case of narrow multiplets). The low-temperature relaxation data follow a phenomenological equation $\tau^{-1}(\mathrm{LT})=F T^{-k}$ with the temperature exponent close to the second solution of the phonon bottleneck effect, $k \sim 1.3$. These data were used as the starting set for a more advanced non-linear fitting procedure by employing a combined equation $\tau^{-1}=G T^{l}+F T^{-k}$. The resulting parameters are listed in Table 3 . Having the relaxation parameters determined, the interpolation/extrapolation curves were drawn as shown in Figure 8. They pass through the experimental points almost perfectly.

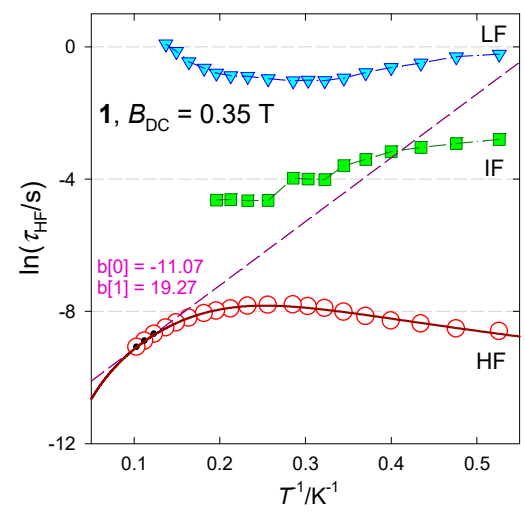

(a)

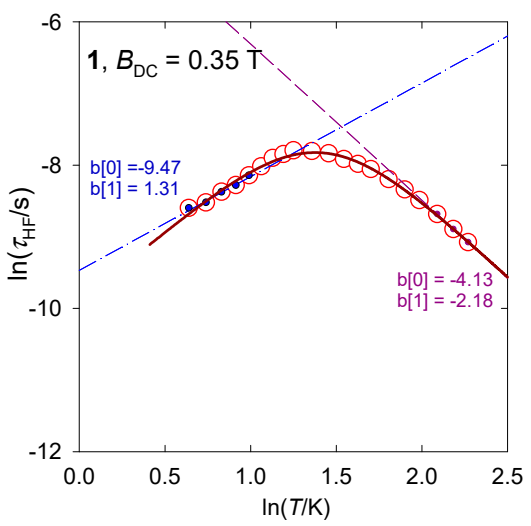

(b)

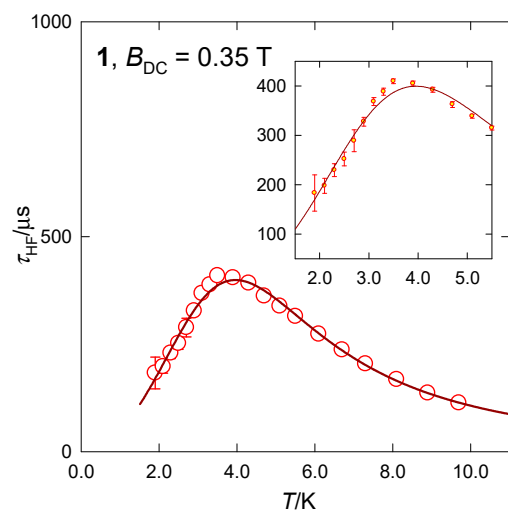

(c)

Figure 8. Various dependences of the high-frequency relaxation time in $\left[\mathrm{Mn}(b z p y)_{4} \mathrm{Cl}_{2}\right]$. Full line-fitted over the whole temperature range with $\tau^{-1}=G T^{l}+F T^{-k}$. (a) Arrhenius-like plot, (b) log-log plot, (c) relaxation time vs temperature. The standard deviations for each data point are displayed in the inset of panel (c). Data adapted from ref. [52]. 2019, American Chemical Society.

The identification of the reciprocal thermal behavior as the second solution of the phonon bottleneck effect is a hypothesis which requires more experimental and theoretical effort. Therefore, we cannot be surprised that sometimes the $k$-exponent floats outside the expectation $(k \sim 1)$. Unanswered is also the coexistence of the quantum tunneling of magnetization that is a temperature independent process. In the limit of temperature far below $2 \mathrm{~K}$ the approximation $\tau^{-1}(\mathrm{LT})=F T^{-k}$ should fail and the quantum tunneling may adopt a leading role.

An indication for the anomalous thermal behavior at low temperature in a mononuclear V(IV) complex has been reported but not analyzed in detail [55]. An anomalous phonon bottleneck effect has been quoted in the lanthanide SIMs [56]. Additional information on the relaxation processes can be found elsewhere [57-61].

\subsection{Cobalt(II) Complexes Showing RTB}

The hexacoordinate complex $[\mathrm{Co}(p y d c a)(d m p y)] \cdot 0.5 \mathrm{H}_{2} \mathrm{O}, 2$, contains two structural units $\mathrm{A}$ and $\mathrm{B}$, both resembling a compressed tetragonal bipyramid along the $\mathrm{N}-\mathrm{Co}-\mathrm{N}$ linkage with a significant angular distortion reducing the $\mathrm{D}_{4 \mathrm{~h}}$ symmetry to $\mathrm{D}_{2 \mathrm{~d}}(\mathrm{O}-\mathrm{Co}-\mathrm{O}$ angles less than $180 \mathrm{deg})$. Ab initio CASSCF calculations using experimental geometries 
show that the lowest excited electronic terms lie at 797 and $2571 \mathrm{~cm}^{-1}$ above the ground term for $\mathrm{A}$ as well as 389 and $1763 \mathrm{~cm}^{-1}$ for $\mathrm{B}$. These are daughter terms of the ${ }^{4} \mathrm{~T}_{1 \mathrm{~g}}$ octahedral mother term on symmetry lowering to the ground ${ }^{4} \mathrm{E}_{\mathrm{g}}$, that further splits into $1^{4} \mathrm{~A}_{1}$ and $2^{4} \mathrm{~A}_{1}$, whereas ${ }^{4} \mathrm{~A}_{1 \mathrm{~g}}$ converts to $3^{4} \mathrm{~A}_{1}$. For the low energy gap, the subsequent evaluation of the spin-Hamiltonian parameters could fail in predicting the sign and value of the $D$-parameter and $g_{z}$ component. Indeed, this is the case (see Table 2). The involvement of the spin-orbit interaction gave the energies of the lowest six Kramers doublets lying at $\delta=0,138,971,1176,2753$, and $2853 \mathrm{~cm}^{-1}$ for A as well as $\delta=0,248,731,997$, 2089 , and $2212 \mathrm{~cm}^{-1}$ for $\mathrm{B}$. The $D$-value extracted from the DC magnetic data (magnetic susceptibility and magnetization) taking into account only the $1^{4} \mathrm{~A}_{1}$ ground electronic term is $D / h c=55 \mathrm{~cm}^{-1}$ [26].

The first scan of the AC susceptibility (Figure 9a) shows that a maximum of the out-of-phase component appears for different frequencies at different fields. A more detailed mapping presented in Figure $9 \mathrm{~b}$ confirms that three relaxation channels are in play. The external magnetic field supports the low-frequency channel at the expense of the high-frequency one that becomes suppressed. Notice, at $T=1.9 \mathrm{~K}$ and $B_{\mathrm{DC}}=0.4 \mathrm{~T}$ the low-frequency relaxation time exceeds $1 \mathrm{~s}: \tau(\mathrm{LF})=1.3 \mathrm{~s}$.

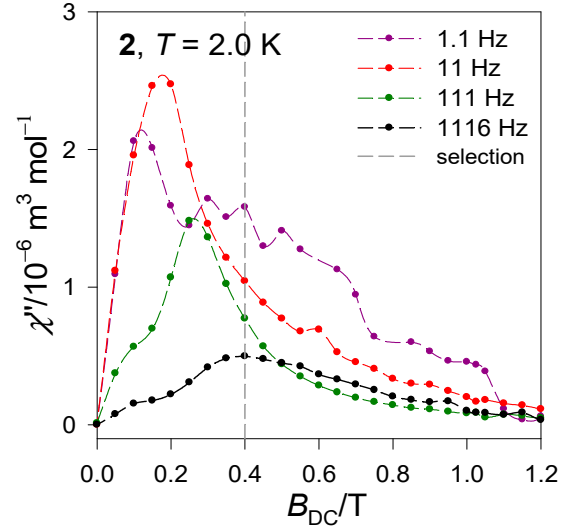

(a)

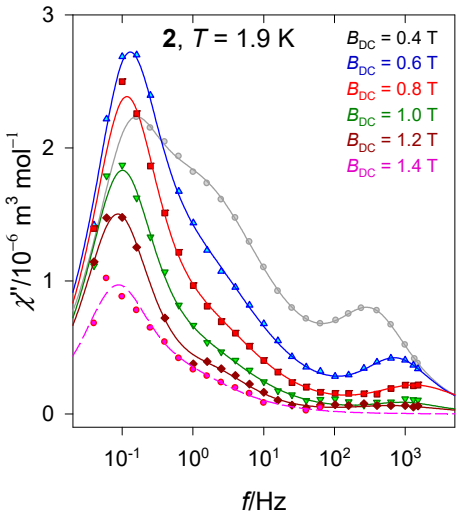

(b)

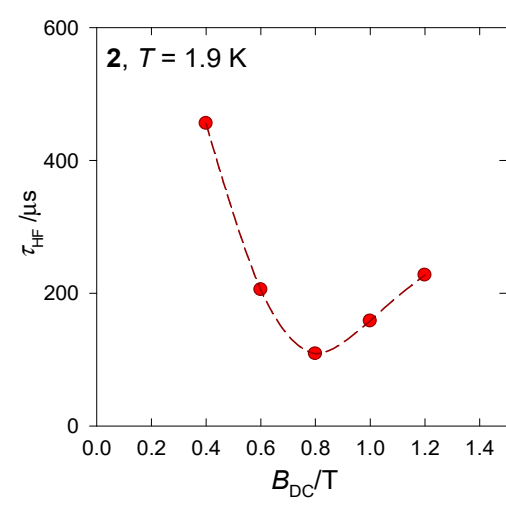

(c)

Figure 9. AC susceptibility and relaxation time for 2 . Solid lines-fitted. (a) field dependence, (b) frequency depenence, (c) relaxation time vs. field.

Figure 10 contains the AC susceptibility data of $22 \chi^{\prime}(f)$ and $22 \chi^{\prime \prime}(f)$ data points for each temperature and the calculated convolution curve based upon 10 free parameters with acceptable standard deviations (Table 5). There is an indication of the isosbestic point at $f \sim 40 \mathrm{~Hz}$.

The fitted relaxation time $\tau_{\mathrm{HF}}$ for the high-frequency channel on cooling from $T=10 \mathrm{~K}$ shows an increase in accordance with existing theories. However, it turns down below $4 \mathrm{~K}$, which reflects an accelerated relaxation. This reciprocating thermal behavior cannot be reproduced by traditional relaxation mechanisms (Orbach, Raman, direct, quantum tunneling). A three-point linear fit in the Arrhenius-like diagram (Figure 10b) would predict the barrier to spin reversal $U_{\text {eff }}=2|D| \sim 53 \mathrm{~cm}^{-1}$. However, $D>0$ detected by magnetometry does not support the Orbach relaxation mechanism.

The high-temperature data can be well fitted by assuming the Raman-like process as evidenced from the linear fit in Figure 10c. The temperature exponent in $\tau_{\text {Raman }}{ }^{-1}=C T^{n}$ is $n=5.9$. The low-temperature tail of the relaxation time can be fitted well by assuming the second (LT) solution for the phonon bottleneck effect, $\tau_{\mathrm{pb}}{ }^{-1}=F T^{-k}$ with $k=0.64$ (not far from the theoretical value of 1). A fitting procedure based upon the combined formula $\tau^{-1}=C T^{n}+F T^{-k}$ gave a slightly modified value $k=0.78$. The reconstructed function for the relaxation time passes through the "experimental" data almost perfectly within the standard deviations shown in Figure 10d. 
$2[\mathrm{Co}(p y d c a)(d m p y)] \cdot 0.5 \mathrm{H}_{2} \mathrm{O}$

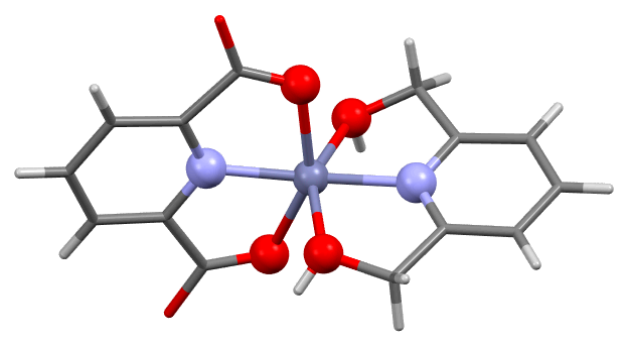

CCDC No 1585697

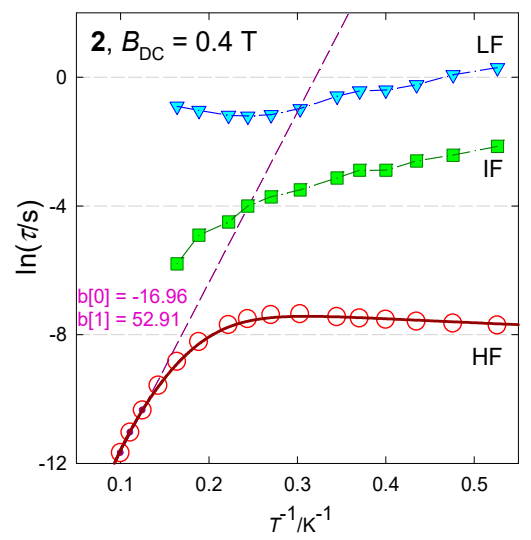

(b)
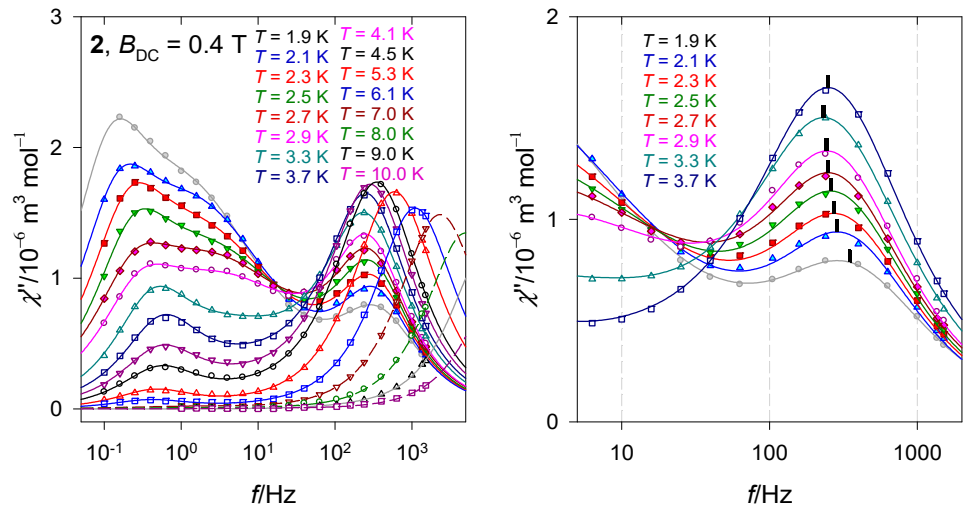

(a)

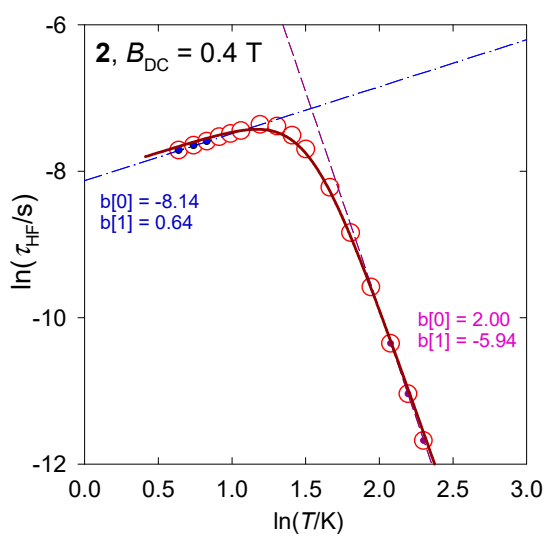

(c)

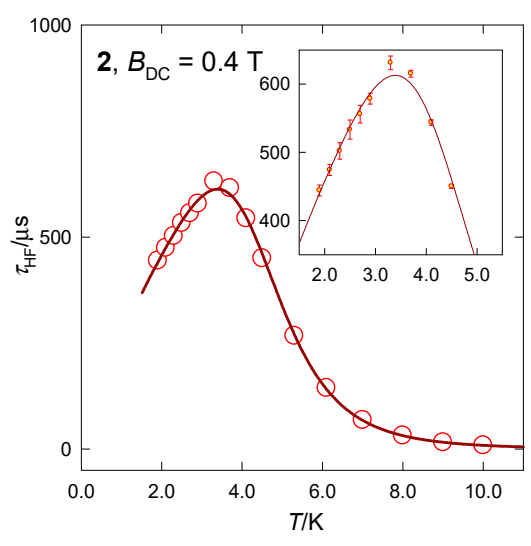

(d)

Figure 10. AC susceptibility and relaxation times for 2. Full lines—fitted. Hydrogen atoms are omitted hereafter. (a) Leftfull scale of data taking, right-zoomed high-frequency range truncated for clarity. (b) Arrhenius-like plot, (c) log-log plot, (d) relaxation time vs. temperature (inset includes the standard deviations as error bars). Data adapted from ref. [26]. 2018, American Chemical Society.

Table 5. Fitted parameters of the three-set Debye model for 2 at $B_{\mathrm{DC}}=0.4 \mathrm{~T}$ including the discrepancy factors and standard deviations.

\begin{tabular}{cccccccc}
\hline $\mathbf{T} / \mathbf{K}$ & $\boldsymbol{R}\left(\chi^{\prime}\right) / \%$ & $\boldsymbol{R}\left(\chi^{\prime \prime}\right) / \%$ & $\boldsymbol{\tau}_{\mathbf{L F}} / \mathbf{s}$ & $\boldsymbol{\tau}_{\mathbf{I F}} / \mathbf{1 0} \mathbf{0}^{-\mathbf{3}} \mathbf{s}$ & $\boldsymbol{\tau}_{\mathbf{H F}} / \mathbf{1 0} \mathbf{0}^{-\mathbf{6}} \mathbf{s}$ & $x_{\mathbf{L F}}$ & $x_{\mathbf{H F}}$ \\
\hline 1.9 & 0.28 & 0.73 & $1.34(5)$ & $107(11)$ & $\mathbf{4 5 6 ( 8 )}$ & 0.28 & 0.14 \\
2.1 & 0.32 & 1.1 & $1.08(2)$ & $89(10)$ & $\mathbf{4 7 4 ( 8 )}$ & 0.23 & 0.16 \\
2.3 & 0.55 & 1.2 & $0.79(2)$ & $74(21)$ & $\mathbf{5 0 2 ( 1 2 )}$ & 0.21 & 0.19 \\
2.5 & 0.57 & 1.5 & $0.67(3)$ & $56(17)$ & $\mathbf{5 3 3 ( 1 4 )}$ & 0.22 & 0.21 \\
2.7 & 0.63 & 1.1 & $0.65(3)$ & $56(23)$ & $\mathbf{5 5 6 ( 1 3 )}$ & 0.14 & 0.25 \\
2.9 & 0.31 & 1.3 & $0.55(2)$ & $44(11)$ & $\mathbf{5 7 9 ( 8 )}$ & 0.14 & 0.31 \\
3.3 & 0.42 & 0.85 & $0.37(1)$ & $30(11)$ & $631(10)$ & 0.20 & 0.46 \\
3.7 & 0.21 & 0.92 & $0.31(1)$ & $24(8)$ & $615(5)$ & 0.17 & 0.59 \\
4.1 & 0.23 & 0.86 & $0.30(1)$ & $18(10)$ & $544(4)$ & 0.14 & 0.69 \\
4.5 & 0.19 & 0.93 & $0.31(1)$ & $11(6)$ & $500(3)$ & 0.11 & 0.76 \\
5.3 & 0.22 & 0.84 & $0.35(2)$ & 7.4 & $267(1)$ & 0.06 & 0.88 \\
6.1 & 0.29 & 0.86 & $0.40(5)$ & 3.0 & $144(1)$ & 0.04 & 0.93 \\
7.0 & 0.24 & 0.66 & - & - & $69(1)$ & & 1 \\
8.0 & 0.14 & 1.7 & & & $32(1)$ & & 1 \\
9.0 & 0.18 & 2.4 & & & $16(1)$ & & 1 \\
10.0 & 0.31 & 5.3 & & & $8.4(7)$ & & 1 \\
\hline
\end{tabular}

Mole fractions of the relaxing species: $x_{\mathrm{LF}}=\left(\chi_{T, \mathrm{LF}}-\chi_{S}\right) /\left(\chi_{T}-\chi_{S}\right), x_{\mathrm{IF}}=\left(\chi_{T, \mathrm{IF}}-\chi_{T, \mathrm{LF}}\right) /\left(\chi_{T}-\chi_{S}\right)$, $x_{\mathrm{HF}}=\left(\chi_{T, \mathrm{HF}}-\chi_{\mathrm{T}, \mathrm{IF}}\right) /\left(\chi_{T}-\chi_{S}\right), \chi_{\mathrm{T}, \mathrm{HF}}=\chi_{T}$, and $x_{\mathrm{IF}}=1-\chi_{\mathrm{LF}}-x_{\mathrm{HF}} . R$-discrepancy factors of fit for the in-phase and out-of-phase susceptibility. A digit in parentheses is the standard deviation. Bold—data showing RTB. 
Doping experiments of 2 into a diamagnetic matrix $(\mathrm{Co}: \mathrm{Zn}=1: 3)$ disclosed that the former three relaxation channels collapse into a single one manifesting itself only in a single peak at $\chi^{\prime \prime}$ vs. $f$ and the RTB effect is lost (Figure 11). Therefore, the LF and eventually also IF channels are of the intermolecular nature and the RBT effect is somehow associated with the multichannel relaxation. An effect of the dilution to the diamagnetic matrix and the field dependence of the relaxation time supports the presence of a kind of direct process, including the PB [56].
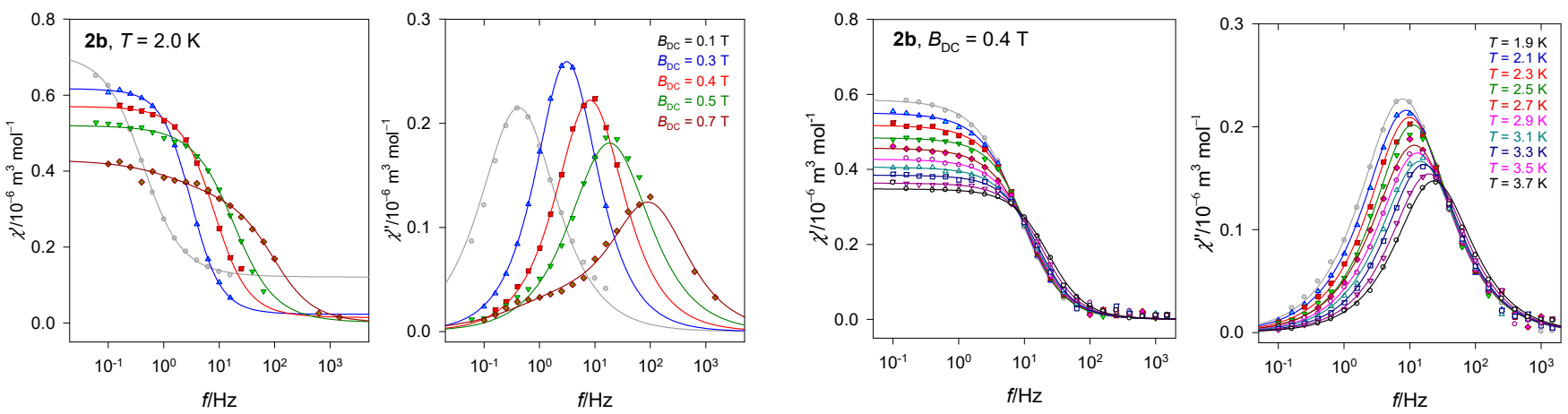

Figure 11. AC susceptibility for a doped sample $\mathrm{C}_{28} \mathrm{H}_{26} \mathrm{Co}_{0.52} \mathrm{~N}_{4} \mathrm{O}_{13} \mathrm{Zn}_{1.48}(\mathbf{2 b})$.

Two hexacoordinate complexes with the same pincer-type structure, [Cu(pydca)(dmpy)] $0.5 \mathrm{H}_{2} \mathrm{O}$ and [Ni(pydca) (dmpy)] $\cdot \mathrm{H}_{2} \mathrm{O}$, also show RTB [53,54] (Table 3).

A complex $\left.\left[\mathrm{Co}(d m p y)_{2}\right](d n b z)_{2}\right]$ containing 2,6-pyridinedimethanol in the coordination sphere and dinitrobenzoato anions also shows the slow magnetic relaxation, however, without RTB in the studied region of temperatures and magnetic fields [27]. The $\ln \tau_{\mathrm{HF}} \mathrm{vs}$. $\ln T$ dependence gave the temperature exponent $l=2.3$ suggesting the phonon bottleneck relaxation process. There is a strong change in the slow magnetic relaxation upon doping to the diamagnetic $\mathrm{Zn}(\mathrm{II})$ matrix (Figure 12).
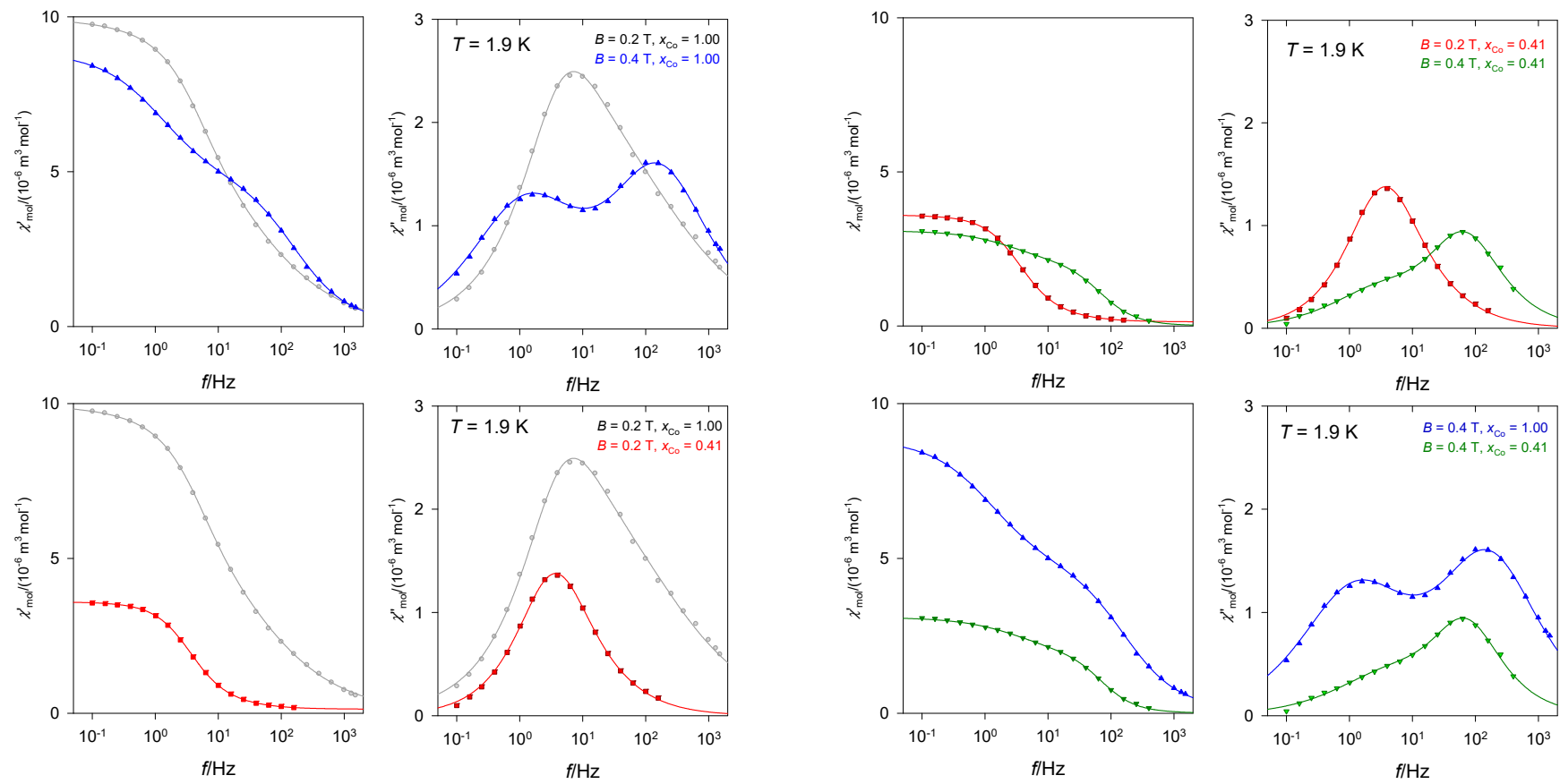

Figure 12. AC susceptibility for $\left.\left[\mathrm{Co}(d m p y)_{2}\right](d n b z)_{2}\right]\left(x_{\mathrm{Co}}=1.00\right)$ and its doped analogue $\mathrm{C}_{28} \mathrm{H}_{24} \mathrm{Co}_{0.41} \mathrm{~N}_{6} \mathrm{O}_{16} \mathrm{Zn}_{0.59}$ $\left(x_{\mathrm{Co}}=0.41\right)$. Data adapted from ref. [27]. 2017, Royal Society of Chemistry. 
The hexacoordinate complex $\left[\mathrm{Co}(b z p y)_{4} \mathrm{Cl}_{2}\right], \mathbf{5}$, contains two structural units with the geometry of the tetragonally distorted octahedron (tetragonal bipyramid) [34]. Despite the fact that the axial $\mathrm{Co}-\mathrm{Cl}$ distances are longer than four equatorial $\mathrm{Co}-\mathrm{N}$ ones, the complex magnetically behaves as a compressed tetragonal bipyramid for which the spinHamiltonian formalism is justified. The $a b$ initio calculations gave $D / h \mathrm{c}=87$ and $124 \mathrm{~cm}^{-1}$, respectively, matching with the susceptibility and magnetization data $D / h c=106 \mathrm{~cm}^{-1}$. It is unlikely that the observed slow magnetic relaxation would proceed at low temperature according to the Orbach mechanism since the energy gap of the ground and excited multiplets, $\Delta=2 D$, is too high and moreover, $D$ is unambiguously positive with no orthorhombic component $E$.

The available AC susceptibility data were successfully fitted by employing the threeor two-set Debye model and the extracted relaxation times are plotted in Figure 13 in several ways. The high-frequency relaxation channel can be analyzed using the combined formula $\tau^{-1}=G T^{l}+F T^{-k}$, where the parameter $G$ is field dependent (unlike the true Raman process that is field independent). The results are listed in Table 3. The increased magnetic field: (i) Favors the low-frequency relaxation channel; (ii) separates the peaks at the LF and HF branches; and (iii) alters the relaxation parameters. The linear fits $\ln \tau$ vs. $\ln T$ gave $l=3.7$ and 2.1 for $B_{\mathrm{DC}}=0.4$ and $0.6 \mathrm{~T}$, respectively, whereas the non-linear fitting procedure results in $l=4.2$ and 3.7. These exponents are too low for the pure Raman process, however, they are too high for the net phonon bottleneck process. The evidence of RBT (probably a second solution of the phonon bottleneck effect) is magnified by the magnetic field: The parameter $k$ increases in the monitored field range.

$5\left[\mathrm{Co}(b z p y)_{4} \mathrm{Cl}_{2}\right]$

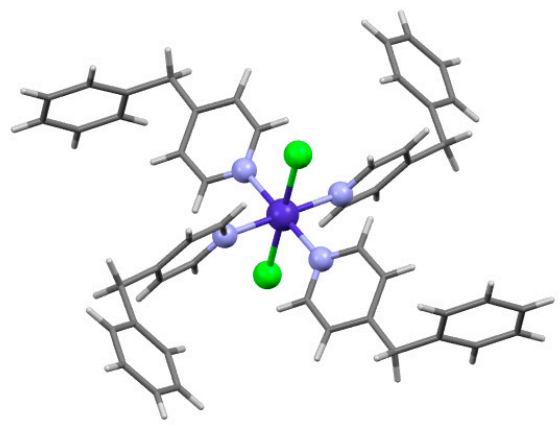

CCDC No 1497488

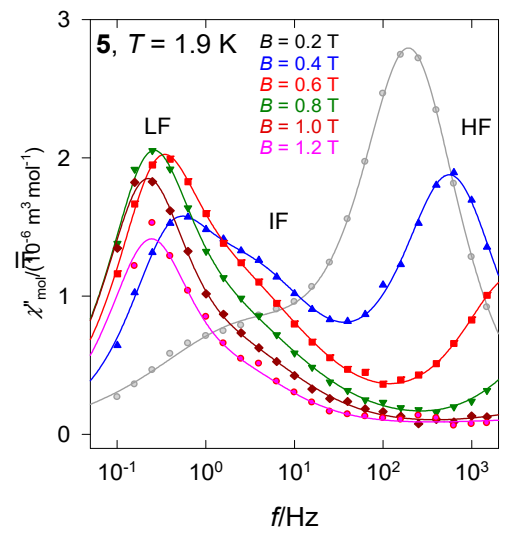

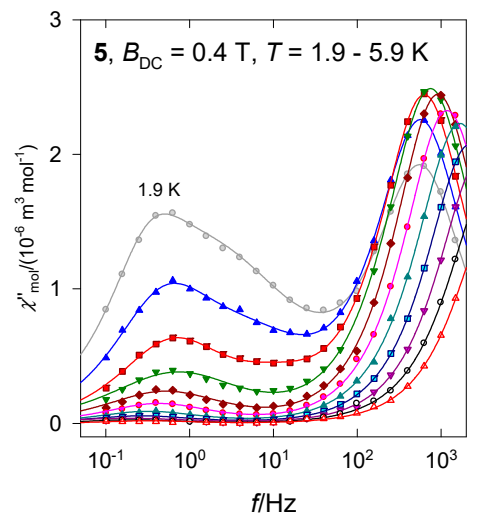

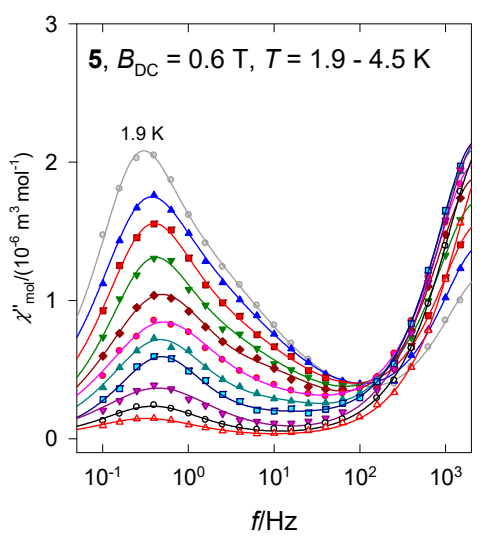

Figure 13. Cont.
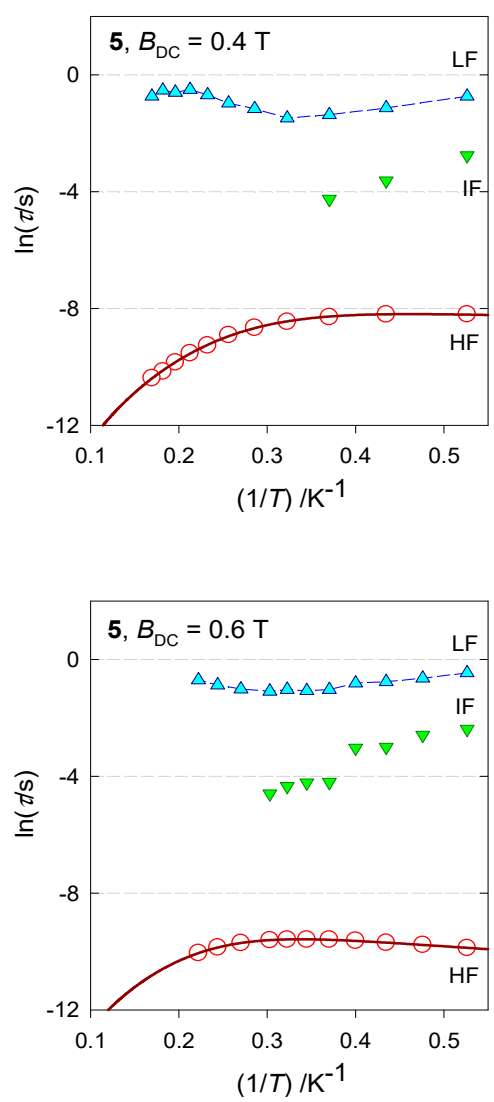

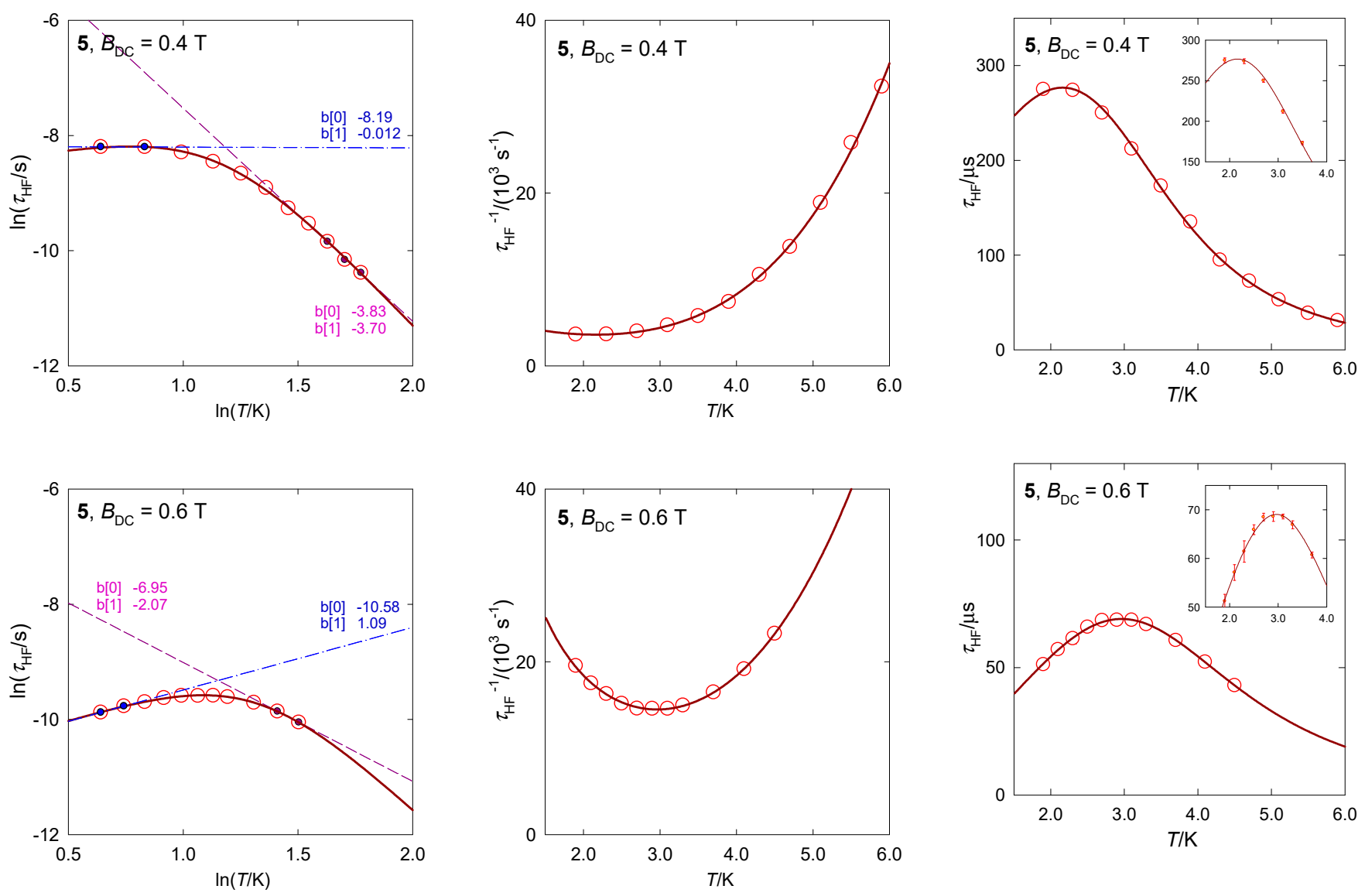

Figure 13. AC susceptibility for 5. Full lines—fitted. Data adapted from ref. [34]. 2017, Wiley-VCH.

The hexacoordinate complex $\left[\mathrm{Co}(b z p y)_{4}(\mathrm{NCS})_{2}\right], 6$, displays characteristics analogous to 5 [29]. Ab initio calculations predict $D / h c=88.6$ and $90.8 \mathrm{~cm}^{-1}$ for the two structural units matching the magnetometric determination $D / h c=90.5 \mathrm{~cm}^{-1}$. These data again discriminate the presence of the Orbach relaxation process. The AC susceptibility confirms two relaxation channels (Figure 14): at $B_{\mathrm{DC}}=0.2 \mathrm{~T}$ the LF channel is seen only as a shoulder at $\chi^{\prime \prime}$ vs. $f$ function, whereas at $B_{\mathrm{DC}}=0.4 \mathrm{~T}$ it refers to a well-developed second, LF peak. The linearized graphs $\ln \tau$ vs. $\ln T$ gave the exponents $l=4.1$ and $k \sim 0$, whereas the nonlinear data fitting resulted in $l=4.3$ and $k=0.4$. These data are close to those obtained for $\left[\mathrm{Co}(b z p y)_{4} \mathrm{Cl}_{2}\right]$ for the same external field $B_{\mathrm{DC}}=0.4 \mathrm{~T}$ (Table 3).

The dinuclear complex $\left[\mathrm{Co}^{\mathrm{III}} \mathrm{Co}^{\mathrm{II}}\left(\mathrm{LH}_{2}\right)_{2}\left(\mathrm{CH}_{3} \mathrm{COO}\right)\left(\mathrm{H}_{2} \mathrm{O}\right)\right]\left(\mathrm{H}_{2} \mathrm{O}\right)_{3}, 7$, contains the magnetically silent center $\mathrm{Co}$ (III) and the magnetically active center $\mathrm{Co}$ (II) possessing the $\left\{\mathrm{CoO}_{6}\right\}$ donor set (Figure 15) [35]. There are no symmetry elements within the chromophore so that the ground state is orbitally non-degenerate. However, it results from the splitting of the mother octahedral term ${ }^{4} \mathrm{~T}_{2 \mathrm{~g}}$ to the $\left\{{ }^{4} \mathrm{E},{ }^{4} \mathrm{~A}\right\}$ daughter terms, and a further symmetry descent generates the three lowest orbital singlets. Ab initio calculations predict the three lowest energy terms lying at 0,353 , and $1250 \mathrm{~cm}^{-1}$ by the CASSCF method and at 0,463 , and $1532 \mathrm{~cm}^{-1}$ by further application of the NEVPT2 diagonal correction. This means that the ground electronic term is quasi degenerate and the application of the spin-Hamiltonian formalism needs to be assessed with care. After inclusion of the spin-orbit interaction, ORCA calculations gave six Kramers doublets lying at the energies 0, 219, 752, 1020, 1867, and $1942 \mathrm{~cm}^{-1}$. The lowest energy gap $\delta_{1}=219 \mathrm{~cm}^{-1}$ has no relationship to the axial zero-field splitting parameter $D$ in the case of the quasi degenerate ground term. However, when the evaluation of the spin-Hamiltonian parameters is activated, incorrect predictions are obtained: $D / h c=-99.6 \mathrm{~cm}^{-1}, E / D=0.26$, and $g\{1.82,2.32,3.08\}$. 


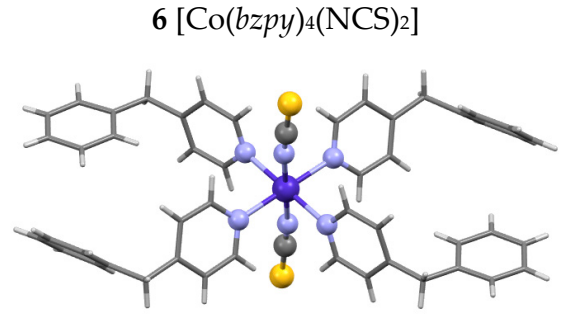

CCDC No 1497489
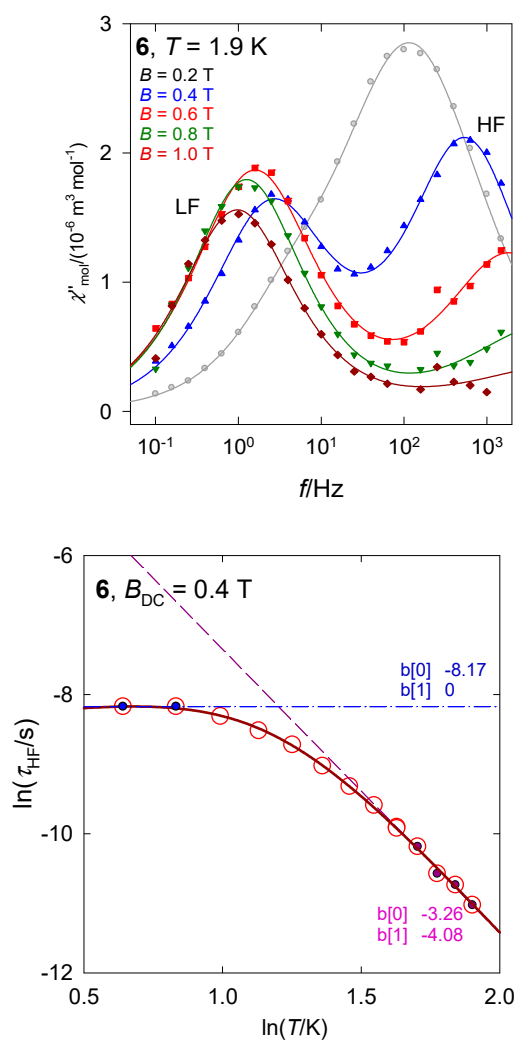
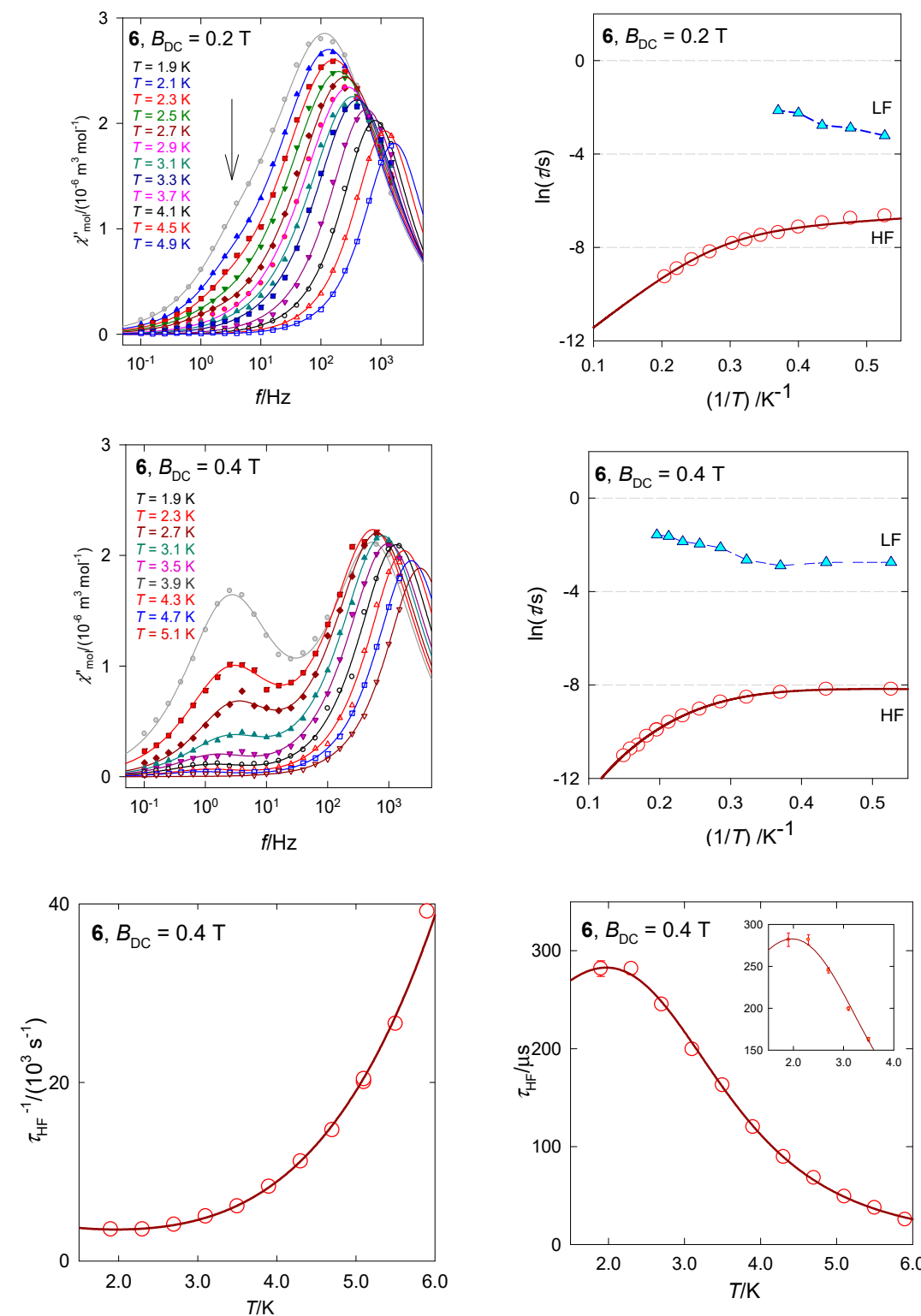

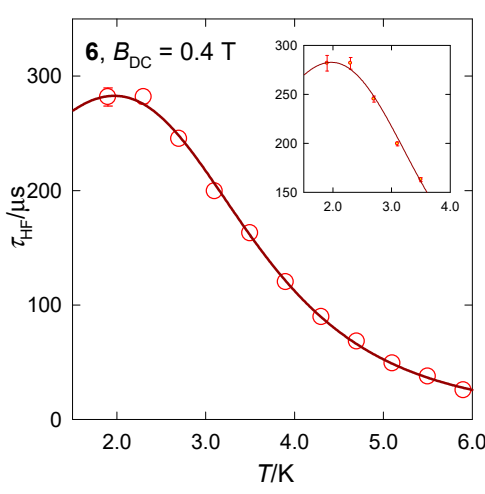

Figure 14. AC susceptibility data for 6. Full lines—fitted. Data adapted from ref. [34]. 2017, Wiley-VCH.

The magnetic susceptibility data in the present case was fitted successfully by utilizing the Griffith-Figgis model with parameters $(A \kappa \lambda) / h c=-176 \mathrm{~cm}^{-1}, g_{\mathrm{L}}=-(A \kappa)=-1.49$, $\Delta_{\mathrm{ax}} / h c=-711 \mathrm{~cm}^{-1}, \Delta_{\mathrm{rh}} / h c=44 \mathrm{~cm}^{-1}$. The magnetic anisotropy is of the easy-axis type as proven by the $3 \mathrm{D}$ visualization of the magnetization (the magnetic field was pointed to the set of grid points distributed uniformly over a sphere).

The AC susceptibility measurements show a two-channel slow magnetic relaxation: The low-frequency relaxation channel is strongly supported by the external magnetic field. Moreover, the RTB is evidenced at $B_{\mathrm{DC}}=0.4 \mathrm{~T}$ and the relaxation time for the HF channel can be fitted with the temperature exponents $l=4.1$ and $k=0.75$.

The pentacoordinate complex $\left[\mathrm{Co}(\right.$ bzimpy $\left.) \mathrm{Cl}_{2}\right], 8$, resembles the geometry of the square pyramid (the SHAPE agreement factor AF(SPY-5) = 1.7) rather than trigonal bipyramid $(\mathrm{AF}(\mathrm{TBPY}-5)=5.0)$, Figure 16 [40]. For the square pyramid of the $\mathrm{C}_{4 \mathrm{v}}$ symmetry the ground electronic term is orbitally degenerate ${ }^{4} \mathrm{E}$. Even at the lowered symmetry the ground and the first excited electronic terms could be quasi-degenerate (separated by $10^{2} \mathrm{~cm}^{-1}$ ) so that the spin Hamiltonian formalism is problematic to apply. An activation of the ab initio evaluation of the D-parameter could lead to false predictions, both in its value and sign. Indeed, the inappropriate calculation yields erroneous results $D / h c=-87 \mathrm{~cm}^{-1}$ 
and $g_{z}=1.86$ that originate in the divergence of the perturbation theory (splitting of terms is only $\Delta / h c=220 \mathrm{~cm}^{-1}$ ). The multiplets (Kramers doublets) arising from the ground electronic term lie at $0,186,559$, and $803 \mathrm{~cm}^{-1}$, but the first gap $\delta / \mathrm{hc}=186 \mathrm{~cm}^{-1}$ has nothing to do with the axial zero-field splitting parameter $D$.

$7\left[\mathrm{Co}^{\mathrm{III}} \mathrm{Co}^{\mathrm{II}}\left(\mathrm{LH}_{2}\right)_{2}\left(\mathrm{CH}_{3} \mathrm{COO}\right)\left(\mathrm{H}_{2} \mathrm{O}\right)\right]$

$\left(\mathrm{H}_{2} \mathrm{O}\right)_{3}$

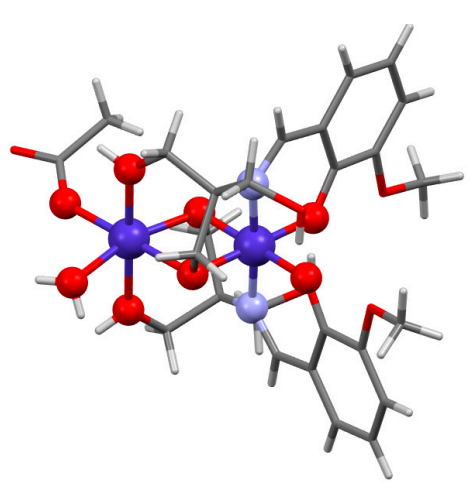

CCDC No 1440294

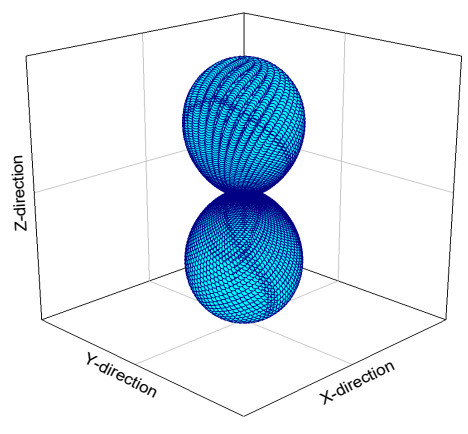

3D model of magnetization

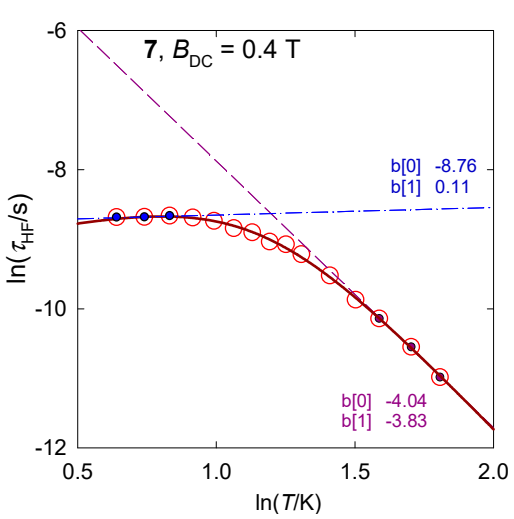

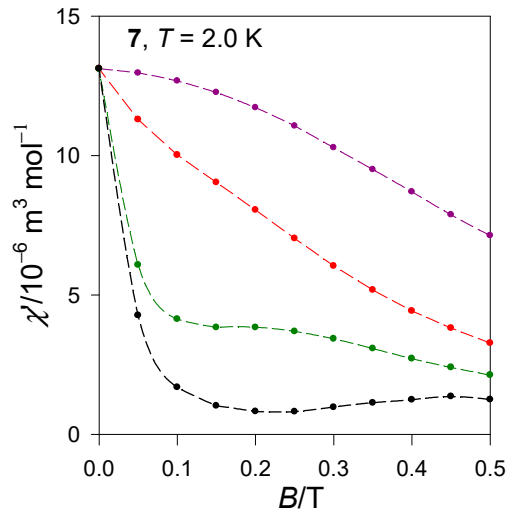
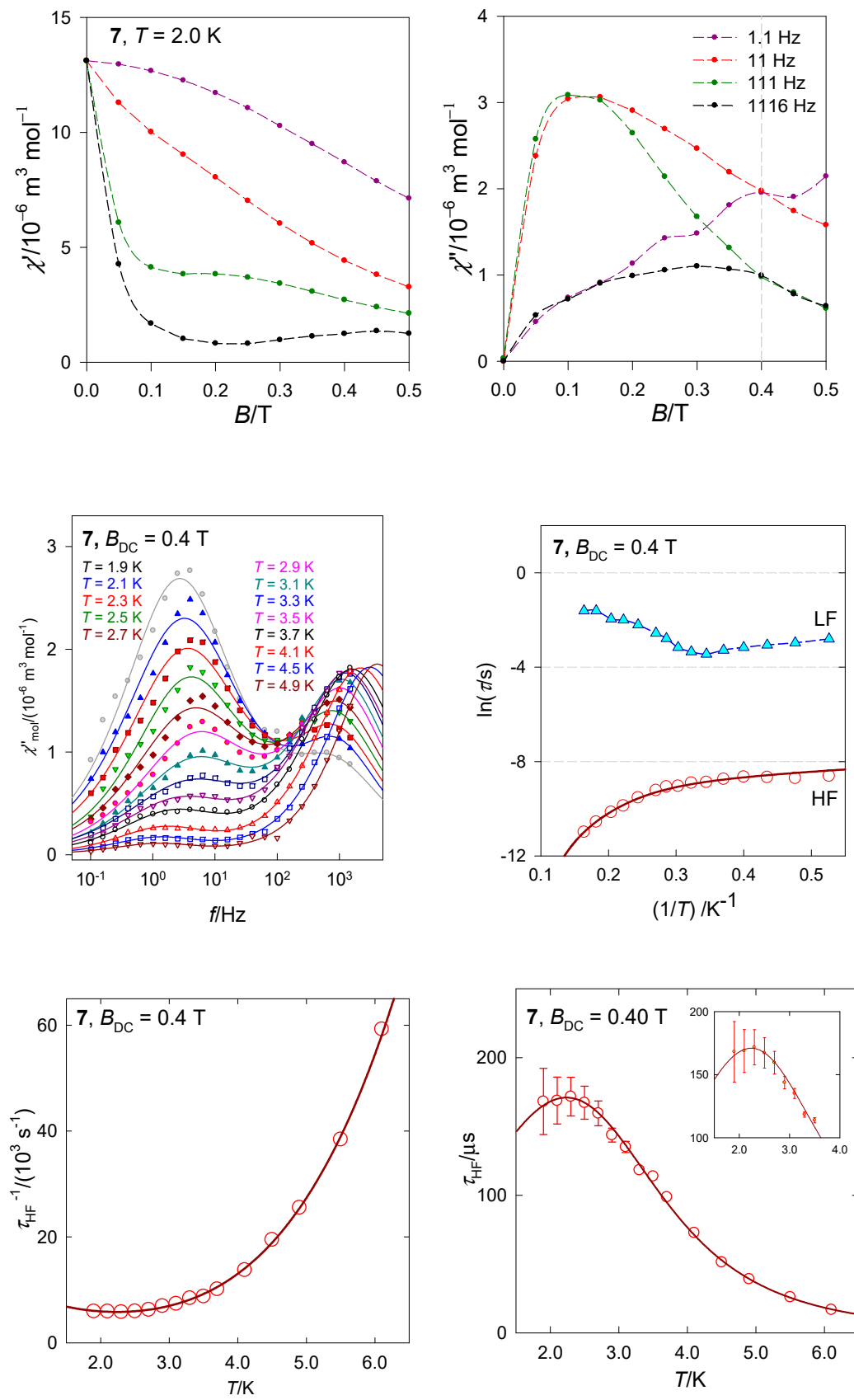

Figure 15. AC susceptibility data for 7. Full lines-fitted. Data adapted from ref. [35]. 2017, American Chemical Society.

The complex $\left[\mathrm{Co}(\right.$ bzimpy $\left.) \mathrm{Br}_{2}\right] \cdot \mathrm{DMF}, 9$, most closely resembles a square pyramid, with the SHAPE agreement factor AF(SPY-5) = 2.1 (for trigonal bipyramid AF(TBPY-5) = 5.4), Figure 17 [40]. The ab initio calculations predict the first excited crystal field term at $\Delta / h c$ $=380 \mathrm{~cm}^{-1}$ and the four lowest multiplets (Kramers doublets) positioned at $\delta=0,138,632$, and $819 \mathrm{~cm}^{-1}$. The calculated value $D / h c=64 \mathrm{~cm}^{-1}$ is not too far from the analysis of DC 
magnetic data, $D / h c=47 \mathrm{~cm}^{-1}$. The calculated $E / D=0.24$ points to an importance of the orthorhombic zfs-parameter $E$, but $g_{z}=1.93$ is still underestimated. The AC susceptibility data show two relaxation channels with visible RTB. The temperature exponents are $n=4.0$ (5.1) and $k=0.75$ (0.56) for $B_{\mathrm{DC}}=0.2$ and $0.4 \mathrm{~T}$, respectively.

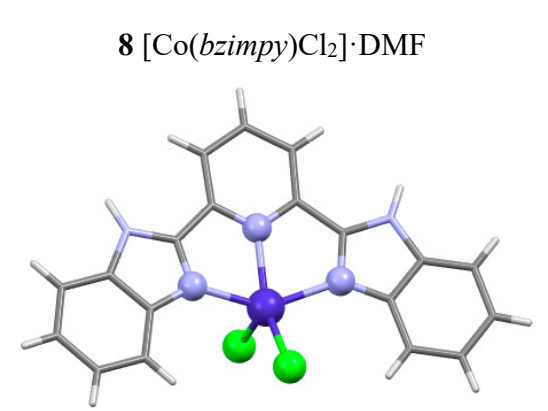

CCDC code WAKJID01
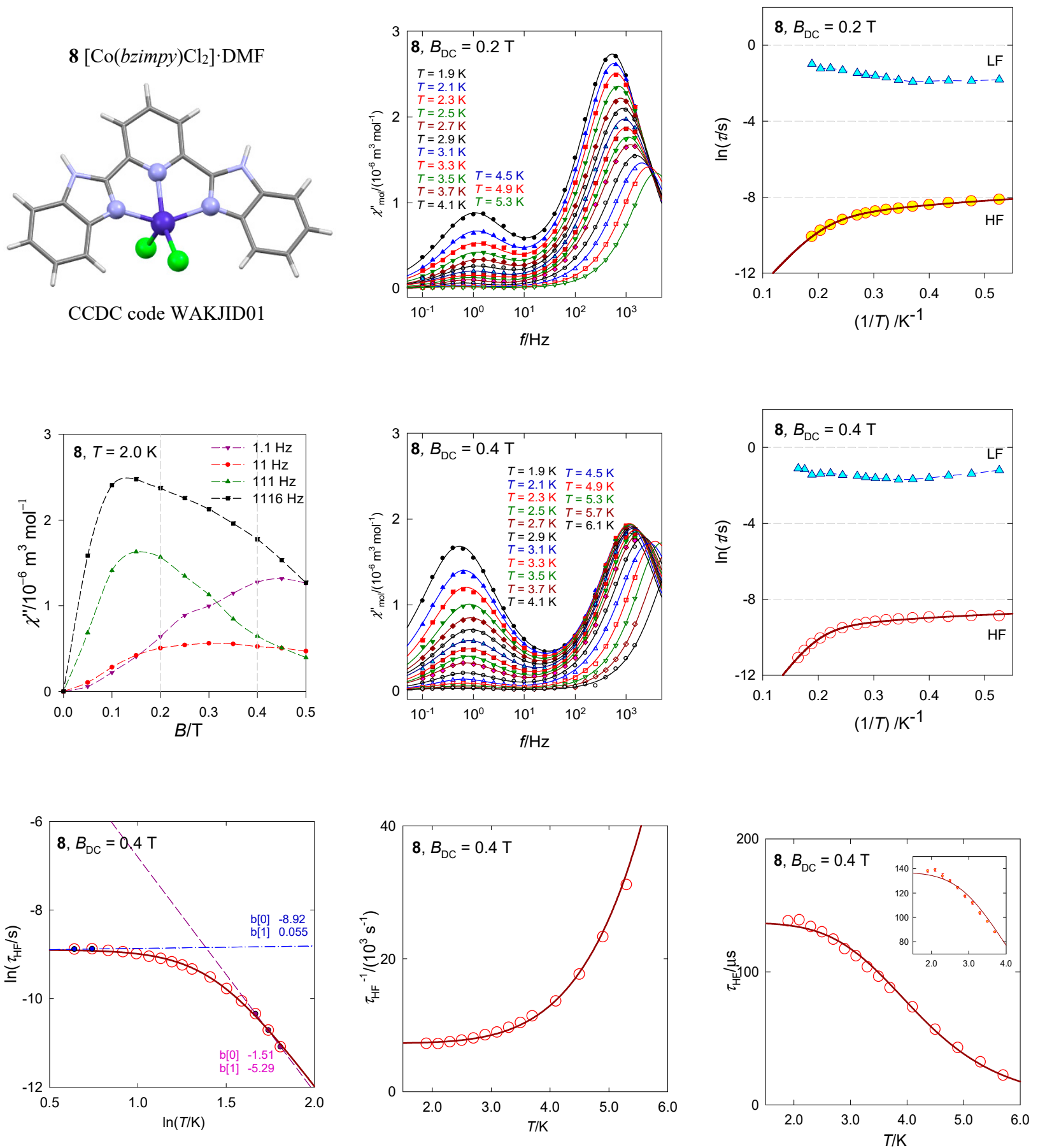

Figure 16. AC susceptibility data for 8. Full lines—fitted. Data adapted from ref. [40]. 2017, Wiley-VCH.

The mononuclear complex $\left[\mathrm{Co}{ }^{\mathrm{II}}\left(\mathrm{PPh}_{3}\right)_{2} \mathrm{Br}_{2}\right], \mathbf{1 0}$, is a tetracoordinate system with rather large negative axial zero-field splitting parameter $D / h c=-13 \mathrm{~cm}^{-1}$ [47]. Since a non-zero out-of-phase susceptibility even at the zero DC field exists, this is a true single-molecule magnet (Figure 18) showing a single relaxation mode. With increasing external field, a low-frequency relaxation channel is opened that is well developed at $B_{\mathrm{DC}}=0.2 \mathrm{~T}$. 


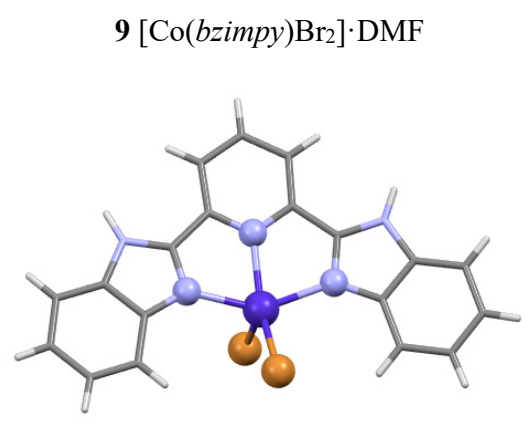

CCDC No 1488937
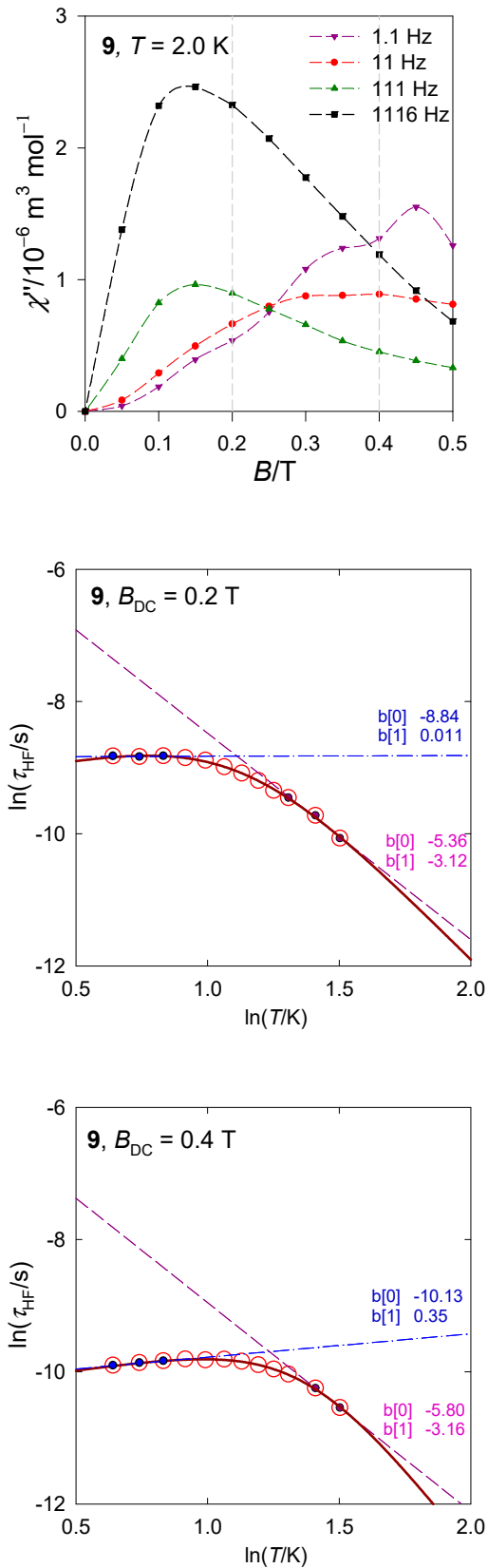
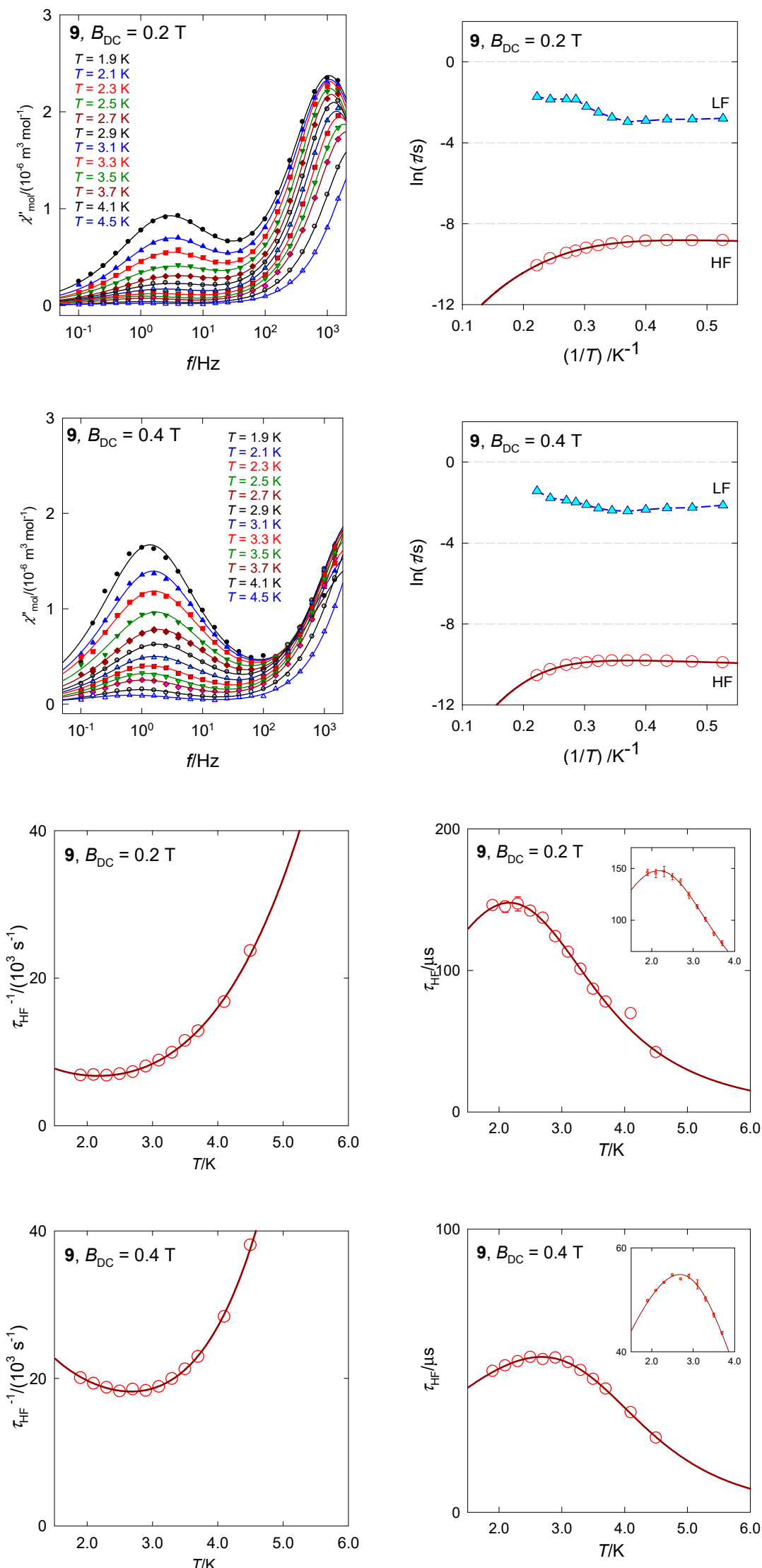

Figure 17. AC susceptibility data for 9. Full lines—fitted. Data adapted from ref. [40]. 2017, Wiley-VCH. 


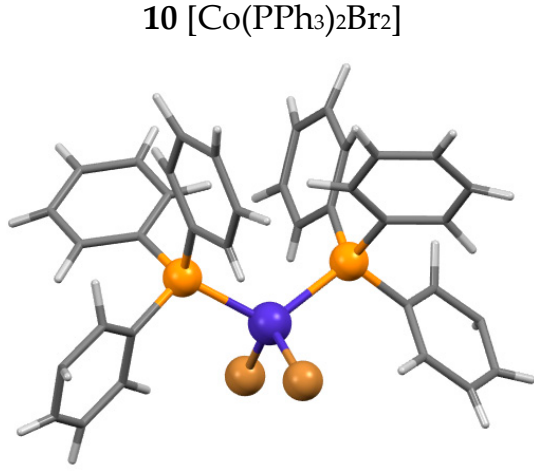

CCDC code BIHGII

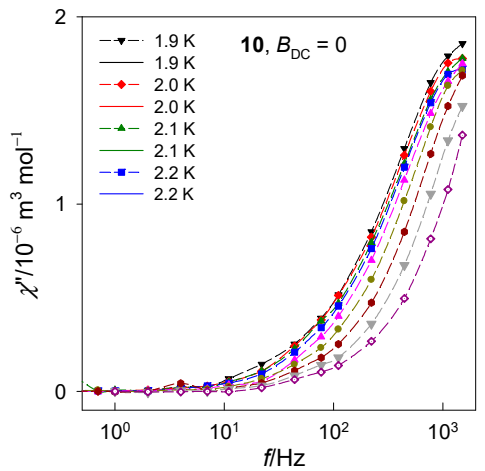

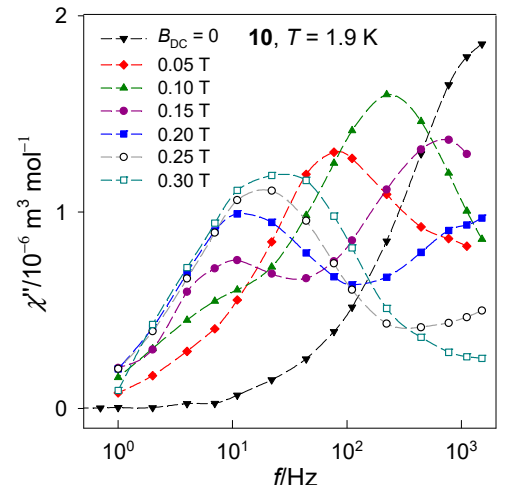
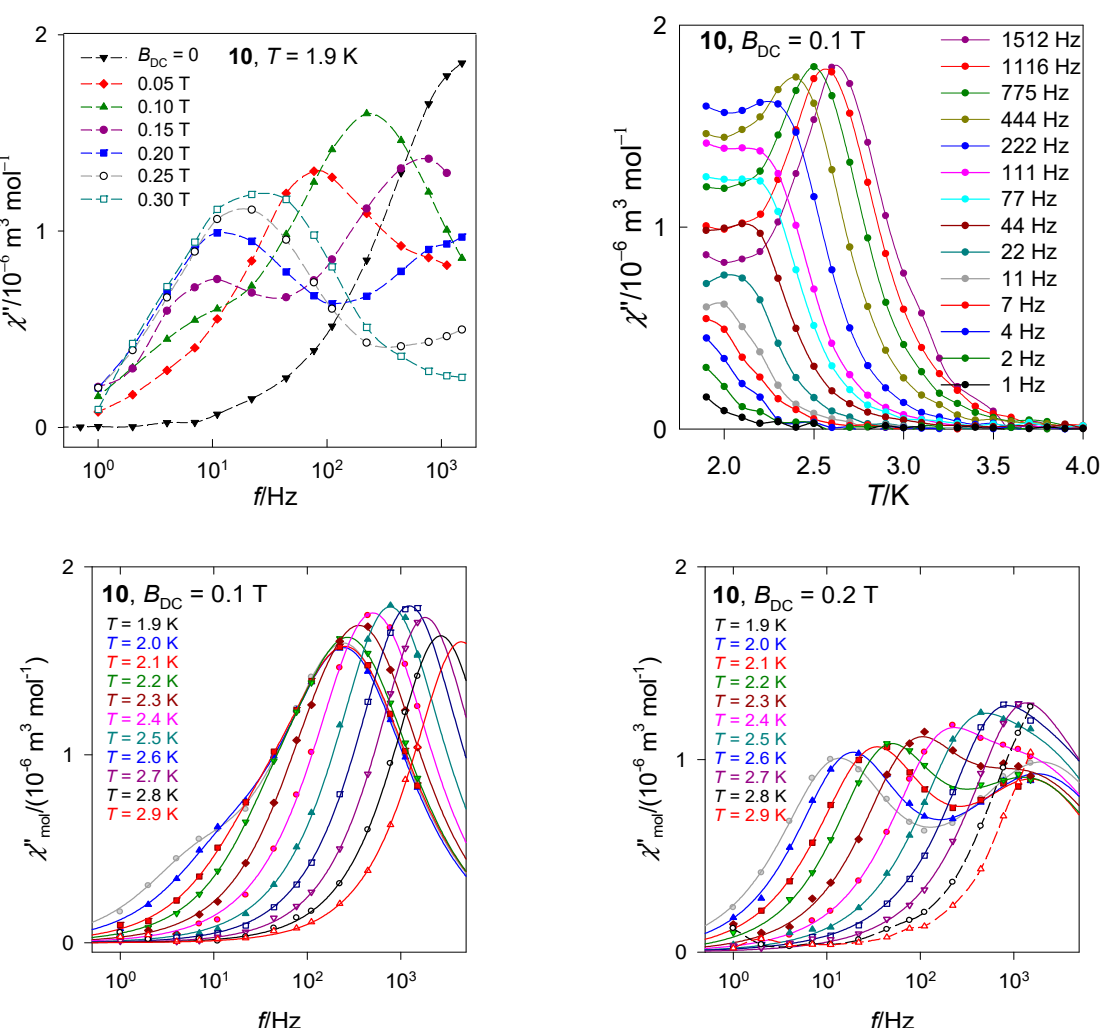

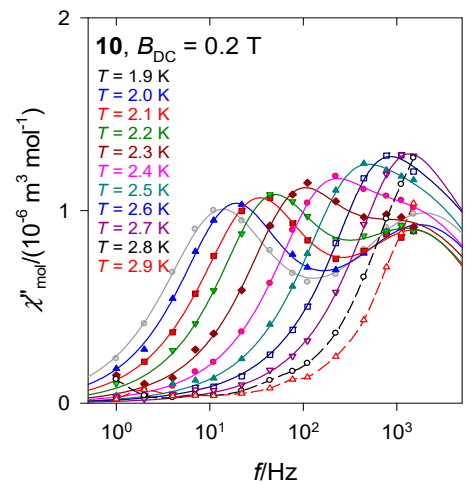

Figure 18. Frequency dependence of the out-of-phase susceptibility at various temperatures and external fields for [Co $\left(\mathrm{PPh}_{3}\right)_{2} \mathrm{Br}_{2}$ ], 10. Solid lines—fitted; dashed-guide for eyes. Data adapted from ref. [47]. 2014, American Chemical Society.

The relaxation time has been plotted in several ways as displayed in Figure 19. Three points from the high-temperature edge of $\ln \tau$ vs. $T^{-1}$ dependence serve for a linear fit yielding the barrier to spin reversal $U_{\mathrm{eff}} / k_{\mathrm{B}}=38$ and $25 \mathrm{~K}$ at $B_{\mathrm{DC}}=0.1$ and $0.2 \mathrm{~T}$, respectively. When the Raman relaxation process is probed as an alternative, $\tau^{-1}=C T^{n}$, then the linear plot $\ln \tau$ vs. $\ln T$ yields exponents $n=13$ and 9 that are far above the border of acceptance for the Raman relaxation process. The RTB behavior is well seen in Figure 19: The relaxation time $\tau$ vs. $T$ on cooling increases with expectations but then decreases at $B_{\mathrm{DC}}=0.2 \mathrm{~T}$.

The tetracoordinate complex $\left[\mathrm{Co}(\right.$ biq $\left.) \mathrm{Cl}_{2}\right], \mathbf{1 1}$, possesses the ground electronic term ${ }^{4} \mathrm{~A}_{1}$ [33] which, according to ab initio calculations, is separated from the first excited term by $\Delta_{1}=1928 \mathrm{~cm}^{-1}$. The calculated value $D / h c=16.1 \mathrm{~cm}^{-1}$ is comparable with the magnetometric analysis yielding $D / h c=10.5 \mathrm{~cm}^{-1}$. The field dependence of the AC susceptibility shows that the out-of-phase component exhibits maxima that depend upon the frequency of the oscillating field (Figure 20). Two external fields, $B_{\mathrm{DC}}=0.2$ and $0.3 \mathrm{~T}$ were selected for subsequent experiments. A detailed scan of the AC susceptibility for 22 frequencies ranging between $f=0.1$ and $1500 \mathrm{~Hz}$ is presented in Figure 20. For $B_{\mathrm{DC}}=0.2 \mathrm{~T}$ the dominant HF peak is accompanied by a minor LF peak and/or shoulder. However, with $B_{\mathrm{DC}}=0.3 \mathrm{~T}$ the LF peak adopts its significance and competes the HF peak. On heating the extinction of the LF peak is faster than that of the HF peak.

The AC susceptibility shows two relaxation channels and the DC magnetic field supports the low-frequency branch. Again, the LF-HF peak separation is observed with the increasing field. At $B_{\mathrm{DC}}=0.2 \mathrm{~T}$, the RTB is not evidenced as opposite to $B_{\mathrm{DC}}=0.4 \mathrm{~T}$ where its on-set is seen. The higher-temperature data can be fitted with the Raman-like term $\tau_{\text {Raman }}{ }^{-1}=C T^{n}$ with $n=5.3$. 

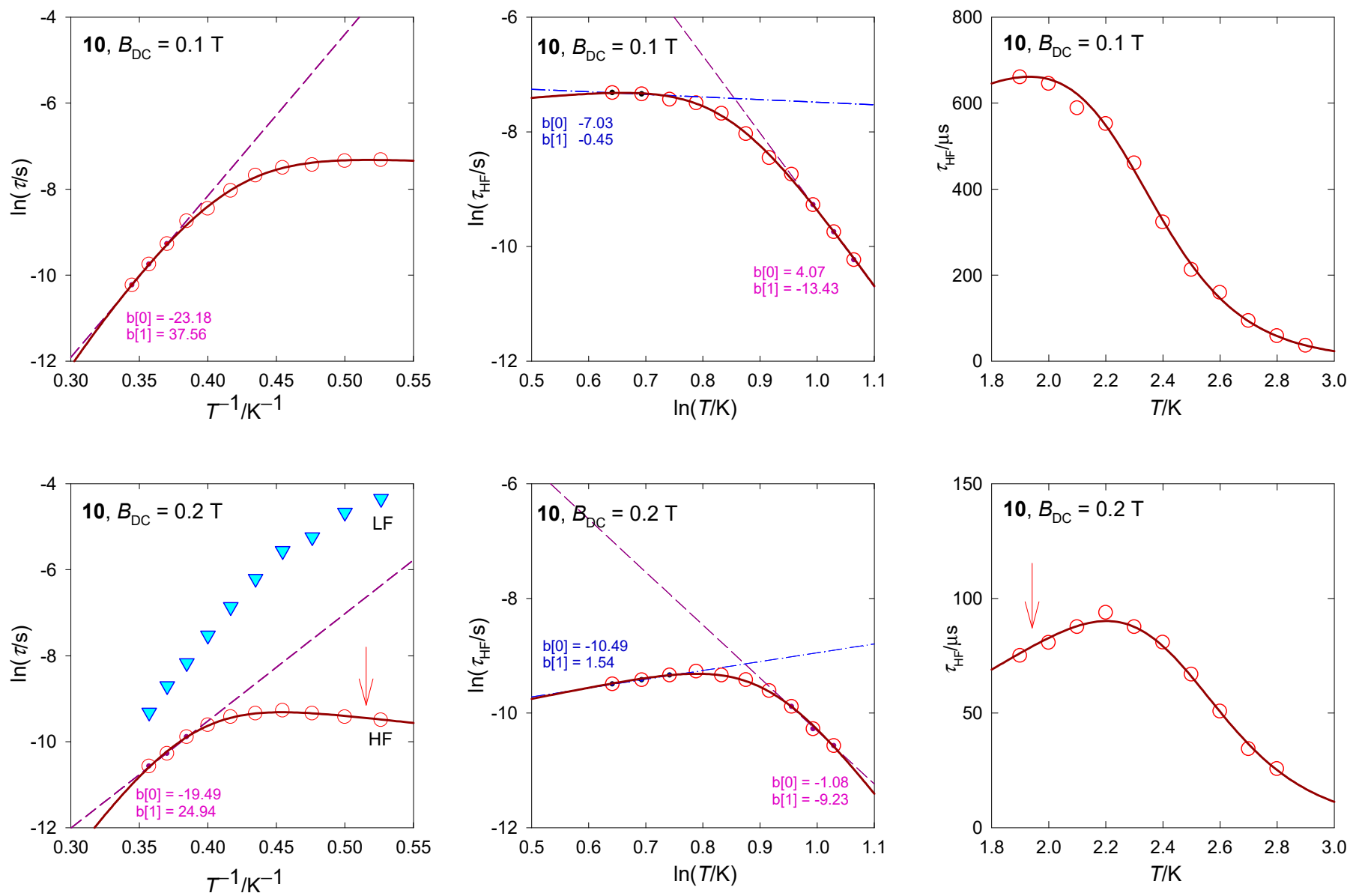

Figure 19. Various dependences of the high-frequency relaxation time in 10. Dashed/dot-dashed-linear fits. Full line-fitted over the whole temperature range using $\tau^{-1}=C T^{n}+F T^{-k}$. An arrow indicates the RTB behavior.

The in-phase and out-of-phase susceptibility components have been fitted by employing the two-set Debye model with seven parameters. Two primitive functions merge to a convoluted envelope that is drawn in Figure 20 as a full line, which passes through the experimental points almost perfectly. The slow magnetic relaxation shows features of the RTB and the relaxation time at $B_{\mathrm{DC}}=0.3 \mathrm{~T}$ can be fitted with the temperature exponents $n=12.0$ and $k=1.0$ (Figure 20). A possible Orbach relaxation mechanism is discriminated by positive $D$. RTB is not identified for $B_{\mathrm{DC}}=0.2 \mathrm{~T}$.

$11\left[\mathrm{Co}(b i q) \mathrm{Cl}_{2}\right]$

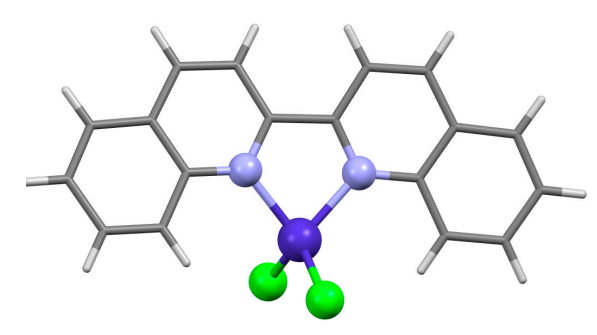

CCDC No 1051392
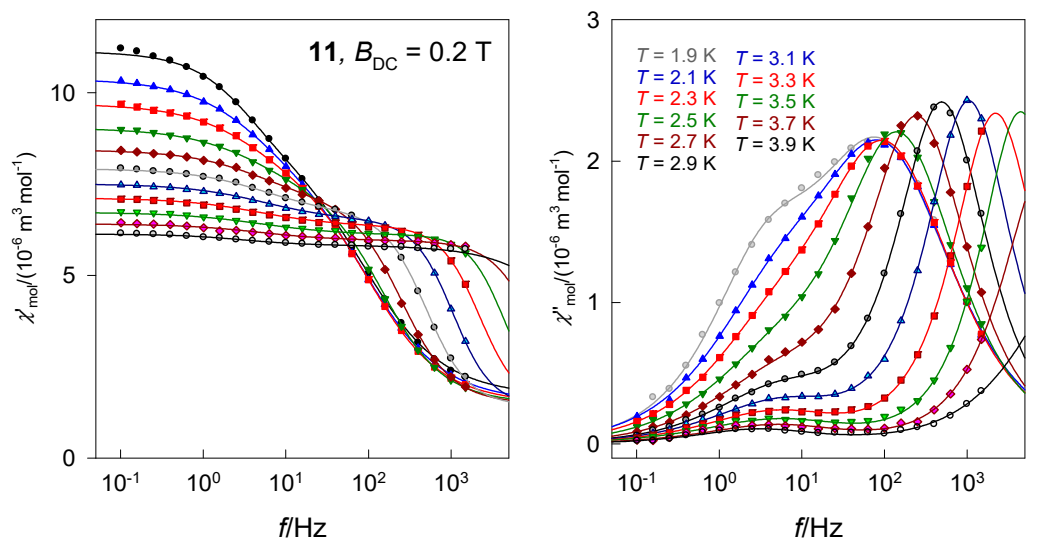

Figure 20. Cont. 

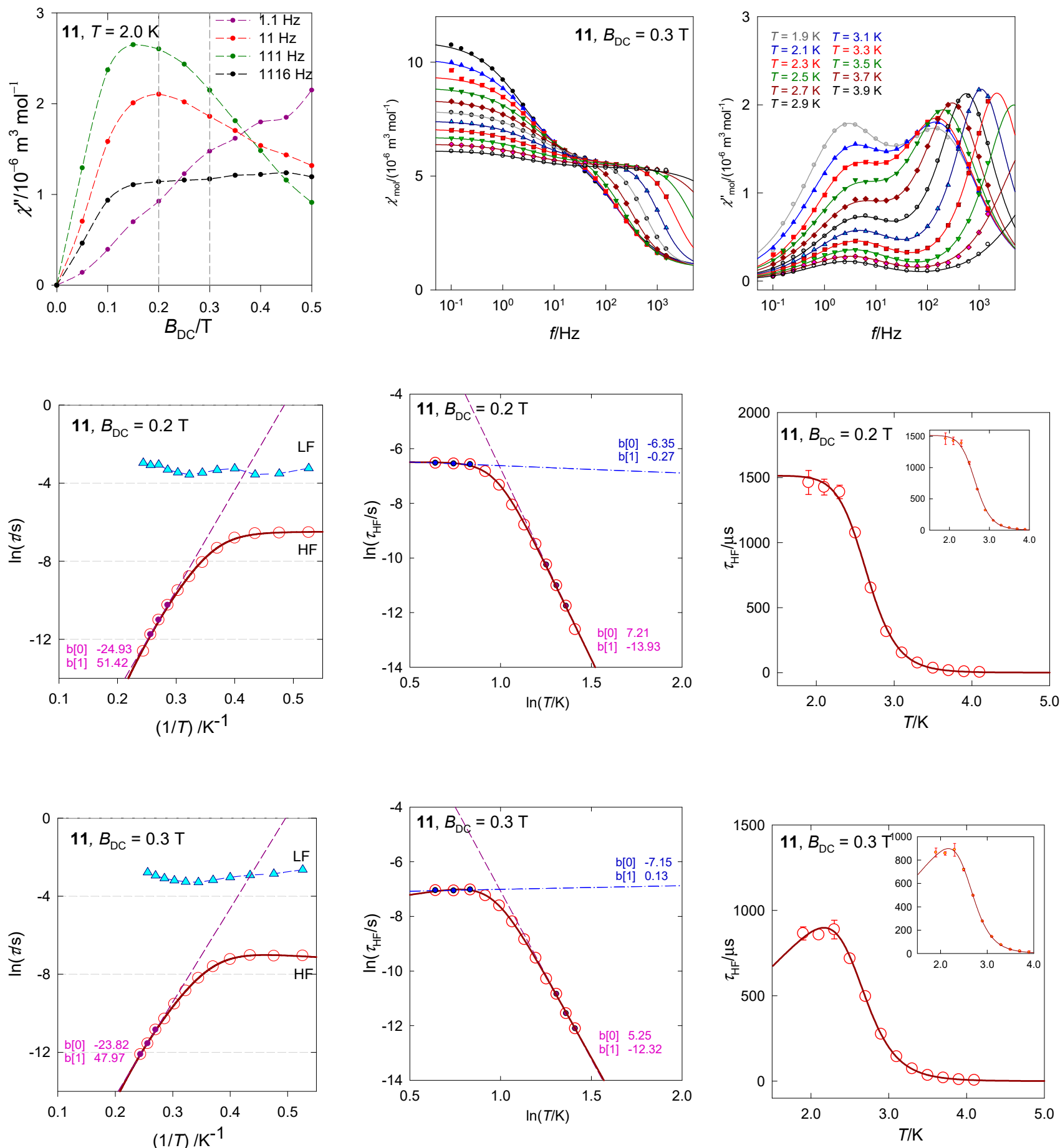

Figure 20. AC susceptibility data for 11. Full lines-fitted. Data adapted from ref. [33]. 2015, Royal Society of Chemistry.

\section{Conclusions}

The slow magnetic relaxation in mononuclear $\mathrm{Co}(\mathrm{II})$ complexes often proceed through two relaxation channels: Low- and high-frequency mode. The external magnetic field supports the low-frequency channel, i.e., the maximum at the out-of-phase susceptibility is moved to lower frequencies (a longer relaxation time), whereas the opposite effect exhibits the high-frequency channel. Some of these complexes show the reciprocating thermal behavior in which a prolongation of the relaxation time on cooling passes through a maximum and then exhibits an acceleration at very low temperatures. Such a behavior cannot be modelled by the traditional relaxation mechanisms covering the Orbach, Raman, 
direct, and quantum tunneling processes since all of them exhibit positive temperature exponents $\tau^{-1} \sim T^{n}, n>0$. RTB, on the contrary, requires $\tau^{-1} \sim T^{-k}, k>0$ and the only theoretical support so far is given by the second solution of the phonon bottleneck effect. However, one can speculate about an alternate hypothesis: The presence of the LF relaxing species causes the concentration of the HF relaxing units to decrease and such a dilution, eventually, can facilitate the relaxation rate.

Supplementary Materials: The following are available online at https://www.mdpi.com/article/ 10.3390/magnetochemistry7060076/s1, Figure S1. Deconvolution curves for the three-set Debye model for 1. Solid line-convolution of three primitive curves (dotted, dashed, dot-dot-dashed). Figure S2. Test of the stability of the fitted relaxation time when 1 to 9 data points from the HF range are gradually omitted. Solid lines for individual fits are overlapped. Dashed lines: primitive low-frequency (LF) and high-frequency (HF) components. Experimental data points from [38] for [Co $(b i q) C 12]$, 12. Figure S3. Test of the stability of the fitted relaxation time when data points from the $\mathrm{HF}$ range are gradually omitted. Experimental data for a doped sample $\mathrm{C}_{28} \mathrm{H}_{26} \mathrm{Co}_{0.52} \mathrm{~N}_{4} \mathrm{O}_{13} \mathrm{Zn}_{1.48}$ (2b). From: Boča, R.; Rajnák, C.; Moncol', J.; Titiš, J.; Valigura, D. Breaking the Magic Border of One Second for Slow Magnetic Relaxation of Cobalt-Based Single Ion Magnets. Inorg. Chem. 2018, 57, 14314-14321. [https:// doi.org/10.1021/acs.inorgchem.8b02287]. Table S1. Stability test of the data fitting with incomplete and/or reduced data points for $\left[\mathrm{Co}(b i q) \mathrm{Cl}_{2}\right], 12$. Data taken at $B_{\mathrm{DC}}=0.2 \mathrm{~T}$ and $T=2.7 \mathrm{~K}$. Table S2. Stability test of the data fitting with incomplete and/or reduced data points for $\left[\mathrm{C}_{28} \mathrm{H}_{26} \mathrm{Co}_{0.52} \mathrm{~N}_{4} \mathrm{O}_{13} \mathrm{Zn}_{1.48}\right], 2 \mathrm{a}$. Data taken at $B_{\mathrm{DC}}=0.4 \mathrm{~T}$ and $T=2.1 \mathrm{~K}$. Table S3. Fitted relaxation time for 5 at $B_{\mathrm{DC}}=0.6 \mathrm{~T}$ with three Debye components.

Author Contributions: All authors contributed equally. All authors have read and agreed to the published version of the manuscript.

Funding: Slovak grant agencies (APVV 19-0087, APVV 18-0016, and VEGA 1/0086/21) are acknowledged for the financial support.

Data Availability Statement: Magnetic data are available from the corresponding author by requirement.

Conflicts of Interest: The authors declare no conflict of interest.

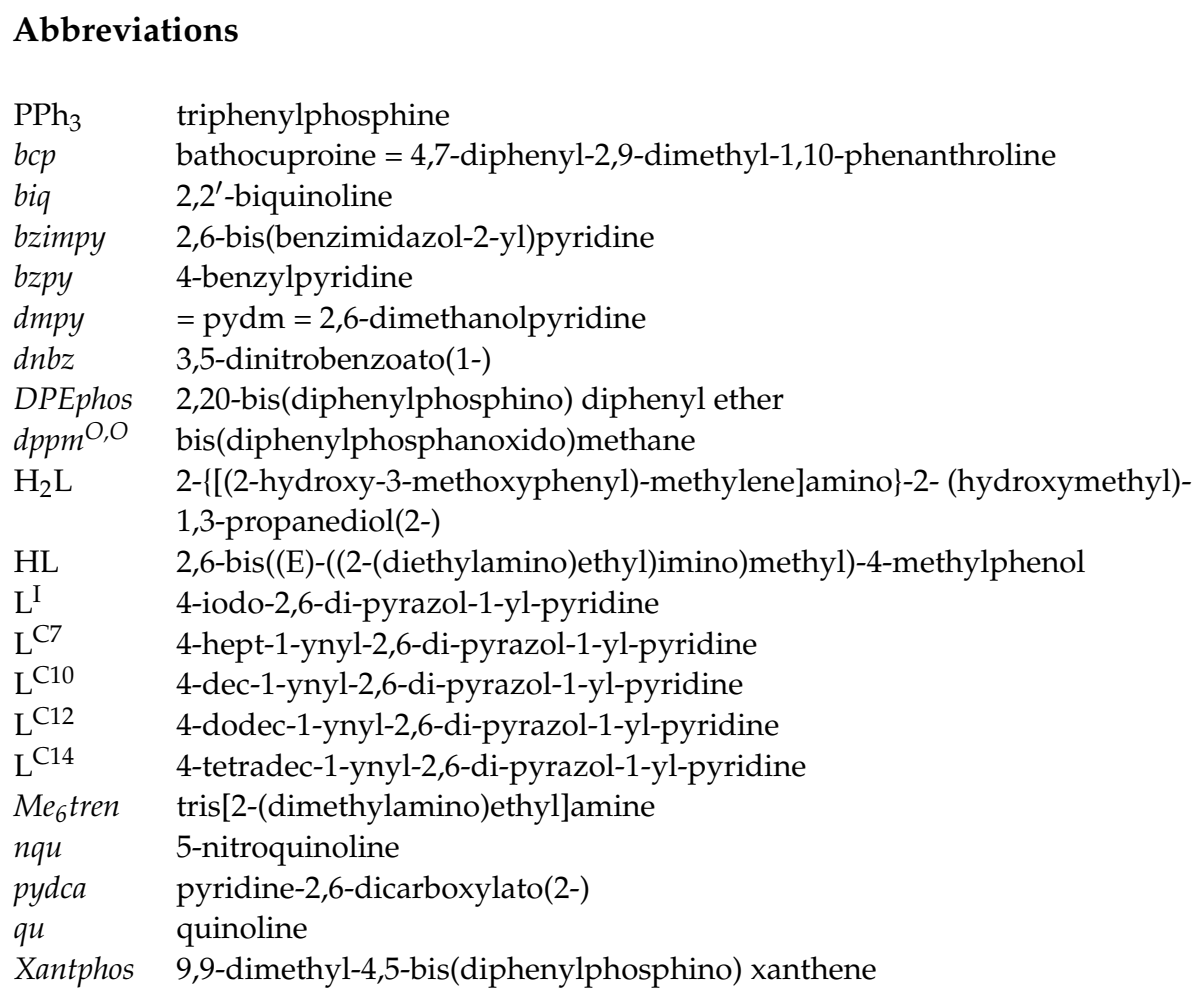




\section{References}

1. Gatteschi, D.; Sessoli, R.; Villain, J. Molecular Nanomagnets; Oxford University Press: Oxford, UK, 2006 ; ISBN 13 9780198567530.

2. Winpenny, R. (Ed.) Single-Molecule Magnets and Related Phenomena; Springer: Berlin/Heidelberg, Germany, 2006; Volume 122, ISBN 978-3-540-33239-8.

3. Benelli, C.; Gatteschi, D. Introduction to Molecular Magnetism: From Transition Metals to Lanthanides; Wiley: Weinheim, Germany, 2015; ISBN 978-3-527-33540-4.

4. Atanasov, M.; Zadrozny, J.M.; Long, J.R.; Neese, F. A theoretical analysis of chemical bonding, vibronic coupling, and magnetic anisotropy in linear iron(II) complexes with single-molecule magnet behavior. Chem. Sci. 2013, 4, 139-156. [CrossRef]

5. Layfield, R.A. Organometallic Single-Molecule Magnets. Organometallics 2014, 33, 1084-1099. [CrossRef]

6. Wernsdorfer, W.; Sessoli, R. Quantum Phase Interference and Parity Effects in Magnetic Molecular Clusters. Science 1999, 284, 133-135. [CrossRef]

7. Rinehart, J.D.; Long, J.R. Exploiting Single-Ion Anisotropy in the Design of f-element Single-Molecule Magnets. Chem. Sci. 2011, 2, 2078-2085. [CrossRef]

8. Gatteschi, D.; Barra, A.L.; Caneschi, A.; Cornia, A.; Sessoli, R.; Sorace, L. EPR of Molecular Nanomagnets. Coord. Chem. Rev. 2006, 250, 1514-1529. [CrossRef]

9. Meng, Y.-S.; Jiang, S.-D.; Wang, B.-W.; Gao, S. Understanding the Magnetic Anisotropy toward Single-Ion Magnets. Acc. Chem. Res. 2016, 49, 2381-2389. [CrossRef] [PubMed]

10. Liddle, S.T.; van Slageren, J. Improving f-element single molecule magnets. J. Chem. Soc. Rev. 2015, 44, 6655-6669. [CrossRef]

11. Woodruff, D.N.; Winpenny, R.E.P.; Layfield, R.A. Lanthanide Single-Molecule Magnets. Chem. Rev. 2013, 113, 5110-5148. [CrossRef]

12. Coulon, C.; Miyasaka, H.; Clérac, R. Single-Chain Magnets: Theoretical Approach and Experimental Systems. Struct. Bonding 2006, 122, 163-206. [CrossRef]

13. Craig, G.A.; Murrie, M. 3d single ion magnets. Chem. Soc. Rev. 2015, 44, 2135-2147. [CrossRef]

14. Gómez-Coca, S.; Aravena, D.; Morales, R.; Ruiz, E. Large magnetic anisotropy in mononuclear metal complexes. Coord. Chem. Rev. 2015, 289-290, 379-392. [CrossRef]

15. Frost, J.M.; Harriman, K.L.M.; Murugesu, M. The rise of 3-d single-ion magnets in molecular magnetism: Towards materials from molecules. Chem. Sci. 2016, 7, 2470-2491. [CrossRef]

16. Boča, R.; Rajnák, C. Unexpected behavior of single ion magnets. Coord. Chem. Rev. 2021, 430, 213657. [CrossRef]

17. Rajnák, C.; Boča, R. Reciprocating thermal behavior in the family of single ion magnets. Coord. Chem. Rev. 2021, $436,213808$. [CrossRef]

18. Abragam, A.; Bleaney, B. Electron Paramagnetic Resonance of Transition Ions; Clarendon Press: Oxford, UK, 1970.

19. Standley, K.J.; Vaughan, R.A. Electron Spin Relaxation Phenomena in Solids; Plenum Press: New York, NY, USA, 1969. [CrossRef]

20. Van Vleck, J.H. Paramagnetic Relaxation Times for Titanium and Chrome Alum. Phys. Rev. 1940, 57, 426-447. [CrossRef]

21. Zadrozny, J.M.; Atanasov, M.; Bryan, A.M.; Lin, C.-Y.; Rekken, B.D.; Power, P.P.; Neese, F.; Long, J.R. Slow magnetization dynamics in a series of two-coordinate iron(II) complexes. Chem. Sci. 2013, 4, 125-138. [CrossRef]

22. Sato, H.; Kathirvelu, V.; Fielding, A.; Blinco, J.P.; Micallef, A.S.; Bottle, S.E.; Eaton, S.S.; Eaton, G.R. Impact of molecular size on electron spin relaxation rates of nitroxyl radicals in glassy solvents between 100 and 300K. Mol. Phys. 2007, 105, 2137-2151. [CrossRef]

23. Abtab, S.M.T.; Majee, M.C.; Maity, M.; Titiš, J.; Boča, R.; Chaudhury, M. Tetranuclear Hetero-Metal $\left[\mathrm{Co}_{2}{ }_{2} \mathrm{Ln}^{\mathrm{III}}{ }_{2}\right]\left(\mathrm{Ln}_{=}=\mathrm{Gd}, \mathrm{Tb}\right.$, Dy, Ho, La) Complexes Involving Carboxylato Bridge in a Rare $\mu 4-\eta 2: \eta 2$ Mode: Synthesis, Crystal Structures and Magnetic Properties. Inorg. Chem. 2014, 53, 1295-1306. [CrossRef] [PubMed]

24. Scott, P.L.; Jeffries, C.D. Spin-Lattice Relaxation in Some Rare-Earth Salts at Helium Temperatures; Observation of the Phonon Bottleneck. Phys. Rev. 1962, 127, 32-51. [CrossRef]

25. Tesi, L.; Lunghi, A.; Atzori, M.; Lucaccini, E.; Sorace, L.; Totti, F.; Sessoli, R. Giant spin-phonon bottleneck effects in evaporable vanadylbased molecules with long spin coherence. Dalton Trans. 2016, 45, 16635-16643. [CrossRef]

26. Boča, R.; Rajnák, C.; Moncol', J.; Titiš, J.; Valigura, D. Breaking the Magic Border of One Second for Slow Magnetic Relaxation of Cobalt-Based Single Ion Magnets. Inorg. Chem. 2018, 57, 14314-14321. [CrossRef]

27. Valigura, D.; Rajnák, C.; Moncol', J.; Titiš, J.; Boča, R. A mononuclear Co(II) complex formed of pyridinedimethanol with manifold slow relaxation channels. Dalton Trans. 2017, 46, 10950-10956. [CrossRef]

28. Casimir, H.B.G.; DuPre, F.K. Note on the thermodynamic interpretation of paramagnetic relaxation phenomena. Physica 1935, 5, 507-511. [CrossRef]

29. Cole, K.S.; Cole, R.H. Dispersion and absorption in dielectrics I. Alternating current characteristics. J. Chem. Phys. 1941, 9, 341-352. [CrossRef]

30. Boča, R. A Handbook of Magnetochemical Formulae; Elsevier: Amsterdam, The Netherlands, 2012. [CrossRef]

31. Boča, R. Struct. Bonding; Springer: Berlin/Heidelberg, Germany, 2006; Volume 117. [CrossRef]

32. Neese, F. The ORCA program system. WIREs Comput. Mol. Sci. 2012, 2, 73-78. [CrossRef]

33. Smolko, L.; Černák, J.; Dušek, M.; Miklovič, J.; Titiš, J.; Boča, R. Three tetracoordinate Co(II) complexes $\left[\mathrm{Co}(\mathrm{biq}) \mathrm{X}_{2}\right](\mathrm{X}=\mathrm{Cl}, \mathrm{Br}, \mathrm{I})$ with easy-plane magnetic anisotropy as field-induced single-molecule magnets. Dalton Trans. 2015, 44, 17565-17571. [CrossRef] [PubMed] 
34. Rajnák, C.; Titiš, J.; Moncol', J.; Renz, F.; Boča, R. Field-Supported Slow Magnetic Relaxation in Hexacoordinate Co ${ }^{\mathrm{II}}$ Complexes with Easy Plane Anisotropy. Eur. J. Inorg. Chem. 2017, 2017, 1520-1525. [CrossRef]

35. Buvaylo, E.A.; Kokozay, V.N.; Vassilyeva, O.Y.; Skelton, B.W.; Ozarowski, A.; Titiš, J.; Vranovičová, B.; Boča, R. Field-Assisted Slow Magnetic Relaxation in a Six-Coordinate Co(II)-Co(III) Complex with Large Negative Anisotropy. Inorg. Chem. 2017, 56, 6999-7009. [CrossRef]

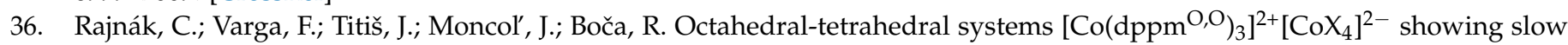
magnetic relaxation with two relaxation modes. Inorg. Chem. 2018, 57, 4352-4358. [CrossRef] [PubMed]

37. Varga, F.; Rajnák, C.; Titiš, J.; Moncol', J.; Boča, R. Slow magnetic relaxation in a Co(II) octahedral-tetrahedral system formed of a $\left[\mathrm{CoL}_{3}\right]^{2+}$ core with $\mathrm{L}=$ bis(diphenylphosphanoxido) methane and tetrahedral $\left[\mathrm{CoBr}_{4}\right]^{2-}$ counter anions. Dalton Trans. 2017, 46, 4148-4151. [CrossRef]

38. Packová, A.; Miklovič, J.; Boča, R. Manifold Relaxation Processes in a Mononuclear Co(II) Single-Molecule Magnet. Polyhedron 2015, 102, 88-93. [CrossRef]

39. Ruamps, R.; Batchelor, L.J.; Guillot, R.; Zakhia, G.; Barra, A.L.; Wernsdorfer, W.; Guihery, N.; Mallah, T. Ising-type magnetic anisotropy and single molecule magnet behaviour in mononuclear trigonal bipyramidal Co(ii) complexes. Chem. Sci. 2014, 5, 3418-3424. [CrossRef]

40. Rajnák, C.; Varga, F.; Titiš, J.; Moncol', J.; Boča, R. Field-Supported Single-Molecule Magnets of Type [Co(bzimpy)X2 ]. Eur. J. Inorg. Chem. 2017, 2017, 1915-1922. [CrossRef]

41. Rajnák, C.; Titiš, J.; Miklovič, J.; Kostakis, G.E.; Fuhr, O.; Ruben, M.; Boča, R. Five mononuclear pentacoordinate Co(II) complexes as field-induced single molecule magnets. Polyhedron 2017, 126, 174-183. [CrossRef]

42. Mandal, S.; Mondal, S.; Rajnák, C.; Titiš, J.; Boča, R.; Mohanta, S. Syntheses, crystal structures and magnetic properties of two mixed-valence $\mathrm{Co}(\mathrm{III}) \mathrm{Co}(\mathrm{II})$ compounds derived from Schiff base ligands: Field supported single-ion-magnet behaviour with easy plane anisotropy. Dalton Trans. 2017, 46, 13135-13144. [CrossRef]

43. Rajnák, C.; Packová, A.; Titiš, J.; Miklovič, J.; Moncol', J.; Boča, R. A tetracoordinate Co(II) single molecule magnet based on triphenylphosphine and isothiocyanato group. Polyhedron 2016, 110, 85-92. [CrossRef]

44. Yang, F.; Zhou, Q.; Zhang, Y.; Zeng, G.; Li, G.; Shi, Z.; Wang, B.; Feng, S. Inspiration from old molecules: Field-induced slow magnetic relaxation in three air-stable tetrahedral cobalt(ii) compounds. Chem. Commun. 2013, 49, 5289-5291. [CrossRef]

45. Titiš, J.; Miklovič, J.; Boča, R. Magnetostructural study of tetracoordinate cobalt(II) complexes. Inorg. Chem. Commun. 2013, 35, 72-75. [CrossRef]

46. Krzystek, J.; Zvyagin, S.A.; Ozarowski, A.; Fiedler, A.T.; Brunold, T.C.; Telser, J. Definitive Spectroscopic Determination of Zero-Field Splitting in High-Spin Cobalt(II). J. Am. Chem. Soc. 2004, 126, 2148. [CrossRef]

47. Boča, R.; Miklovič, J.; Titiš, J. Simple Mononuclear Cobalt(II) Complex: A Single-Molecule Magnet Showing Two Slow Relaxation Processes. Inorg. Chem. 2014, 53, 2367-2369. [CrossRef] [PubMed]

48. Saber, M.R.; Dunbar, K.R. Ligands effects on the magnetic anisotropy of tetrahedral cobalt complexes. Chem. Commun. 2014, 50, 12266-12269. [CrossRef]

49. Smolko, L.; Černák, J.; Dušek, M.; Titiš, J.; Boča, R. Tetracoordinate Co(II) Complexes Containing Bathocuproine and Single Molecule Magnetism. New J. Chem. 2016, 40, 6593-6598. [CrossRef]

50. Huang, W.; Liu, T.; Wu, D.; Cheng, J.; Ouyang, Z.W.; Duan, C. Field-induced slow relaxation of magnetization in a tetrahedral Co(ii) complex with easy plane anisotropy. Dalton Trans. 2013, 42, 15326-15331. [CrossRef]

51. Smolko, L.; Černák, J.; Kuchár, J.; Rajnák, C.; Titiš, J.; Boča, R. Field-Induced Slow Magnetic Relaxation in Mononuclear Tetracoordinate Cobalt(II) Complexes Containing a Neocuproine Ligand. Eur. J. Inorg. Chem. 2017, 2017, 3080-3086. [CrossRef]

52. Rajnák, C.; Titiš, J.; Moncol, J.; Mičová, R.; Boča, R. Field induced slow magnetic relaxation in a mononuclear Mn(II) complex. Inorg. Chem. 2019, 58, 991-994. [CrossRef] [PubMed]

53. Boča, R.; Rajnák, C.; Titiš, J.; Valigura, D. Field Supported Slow Magnetic Relaxation in a Mononuclear Cu(II) Complex. Inorg. Chem. 2017, 56, 1478-1482. [CrossRef]

54. Titiš, J.; Rajnák, C.; Valigura, D.; Boča, R. Field influence on the slow magnetic relaxation of nickel-based single ion magnets. Dalton Trans. 2018, 47, 7879-7882. [CrossRef]

55. Atzori, M.; Tesi, L.; Morra, E.; Chiesa, M.; Sorace, L.; Sessol, R. Room-Temperature Quantum Coherence and Rabi Oscillations in Vanadyl Phthalocyanine: Toward Multifunctional Molecular Spin Qubits. J. Am. Chem. Soc. 2016, 138, 2154-2157. [CrossRef]

56. Rousset, E.; Piccardo, M.; Boulon, M.E.; Gable, R.W.; Soncini, A.; Sorace, L.; Boskovic, C. Slow Magnetic Relaxation in Lanthanoid Crown Ether Complexes: Interplay of Raman and Anomalous Phonon Bottleneck Processes. Chem. A Eur. J. 2018, 24, 14768-14785. [CrossRef]

57. Ray, R.; Avdoshenko, S.M. Insights in Magnetodynamics from a Simple Two-Level Model. ChemRxiv 2020. [CrossRef]

58. Balanda, M. AC Susceptibility Studies of Phase Transitions and Magnetic Relaxation: Conventional, Molecular and LowDimensional Magnets. Acta Phys. Pol. 2013, 124, 964-976. [CrossRef]

59. Freude, D.; Haase, J. Quadrupole Effects in Solid-State Nuclear Magnetic Resonance. In Special Applications; NMR Basic Principles and Progress Series; Pfeifer, H., Barker, P., Eds.; Springer: Berlin/Heidelberg, Germany, 1993; Volume 29. [CrossRef] 
60. Chiorescu, I.; Wernsdorfer, W.; Müller, A.; Bögge, H.; Barbara, B. Butterfly Hysteresis Loop and Dissipative Spin Reversal in the $S$ =1/2, V15 Molecular Complex. Phys. Rev. Lett. 2000, 84, 3454-3457. [CrossRef]

61. Madsen, D.E.; Hansen, M.F.; Mørup, S. The correlation between superparamagnetic blocking temperatures and peak temperatures obtained from ac magnetization measurements. J. Phys. Condens. Matt. 2008, 20, 345209. [CrossRef] 